\title{
Large-Scale Variability in the Midlatitude Subtropical and Subpolar North Pacific Ocean: Observations and Causes
}

\author{
Bo QIU \\ Department of Oceanography, University of Hawaii at Manoa, Honolulu, Hawaii
}

(Manuscript received 26 January 2001, in final form 1 June 2001)

\begin{abstract}
Altimetric data from the 8-yr TOPEX/Poseidon (T/P) mission (Oct 1992-Jul 2000) are used to investigate large-scale circulation changes in the three current systems of the midlatitude North Pacific Ocean: the North Pacific Current (NPC), the Alaska gyre, and the western subarctic gyre (WSG). To facilitate the understanding of the observed changes, a two-layer ocean model was adopted that includes first-mode baroclinic Rossby wave dynamics and barotropic Sverdrup dynamics. The NPC intensified steadily over the T/P period from 1992 to 1998. Much of this intensification is due to the persistent sea surface height (SSH) drop on the northern side of the NPC. A similar SSH trend is also found in the interior of the Alaska gyre. Both of these SSH changes are shown to be the result of surface wind stress curl forcing accumulated along the baroclinic Rossby wave characteristics initiated from the eastern boundary. In addition to the interior SSH signals, the intensity of the Alaska gyre is shown to depend also on the SSH anomalies along the Canada/Alaska coast, and these anomalies are shown to be jointly determined by the signals propagating from lower latitudes and those forced locally by the alongshore surface winds. The WSG changed interannually from a zonally elongated gyre in 1993-95 to a zonally more contracted gyre in 1997-99. This structural change is due to the interannual SSH anomalies within the WSG as a result of the baroclinic Rossby wave adjustment attenuated by eddy dissipation. Along the western boundary of the subpolar North Pacific, variability of the East Kamchatka Current (EKC) and Oyashio is in balance with that of the interior Sverdrup flow on the annual and year-to-year timescales. On the multiyear timescales, the EKC/Oyashio variability is shown to be determined by the baroclinic SSH signals.
\end{abstract}

\section{Introduction}

Large-scale interior circulations in the North Pacific Ocean north of $32^{\circ} \mathrm{N}$ consist of four major current systems: the Kuroshio Extension, the North Pacific Current (NPC), the Alaska gyre, and the western subarctic gyre (WSG) (see Fig. 1). The Kuroshio Extension is the offshore extension of the western boundary current of the North Pacific subtropical gyre (Kawai 1972). It is an eastward inertial jet characterized by large-amplitude meanders and vigorous pinched-off eddies (e.g., Mizuno and White 1983). The Kuroshio Extension loses these inertial current characteristics around the date line, and thereafter it broadens to become the eastward flowing North Pacific Current (White 1982). After encountering the North America coast, the NPC bifurcates. In addition to forming the coastal California Current, the southern branch of the NPC veers southward and joins the interior Sverdrup flow of the subtropical gyre. The northern branch of the NPC forms the origin of the Alaska Current and constitutes the eastern limb of the Alaska gyre

Corresponding author address: Dr. Bo Qiu, Department of Oceanography, University of Hawaii at Manoa, 1000 Pope Road, Honolulu, HI 96822.

E-mail: bo@soest.hawaii.edu
(Chelton and Davis 1982). After veering southwestward at the apex of the Gulf of Alaska, the Alaska Current is renamed the Alaskan Stream. Flowing southwestward along the Aleutian Islands, the Alaskan Stream constitutes the western boundary current of the Alaska gyre (e.g., Favorite et al. 1976; Reed 1984; Musgrave et al. 1992).

As the Alaskan Stream flows farther westward, part of it enters the Bering Sea through deep passages along the Aleutian Islands between $168^{\circ}$ and $172^{\circ} \mathrm{E}$. The remaining continues westward along the southern edge of the Aleutian Islands and constitutes the northern limb of the western subarctic gyre. Upon reaching the Kamchatka peninsula, the Alaskan Stream turns southwestward to form the western boundary current of the WSG: the East Kamchatka Current and its southern continuation, the Oyashio. The WSG is closed to the south by the Subarctic Current after the Oyashio veers eastward around $42^{\circ} \mathrm{N}$, east of Hokkaido (Favorite et al. 1976).

In contrast to this picture of the large-scale mean circulation, our knowledge about the variability in the midlatitude North Pacific is more fragmentary. Although regional long-term measurements exist (a good example of this is the P-line of repeat hydrographic surveys across the Alaska Current; see Tabata 1991), 
(a) Mean sea surface dynamic topography $(0 / 1000 \mathrm{db})$

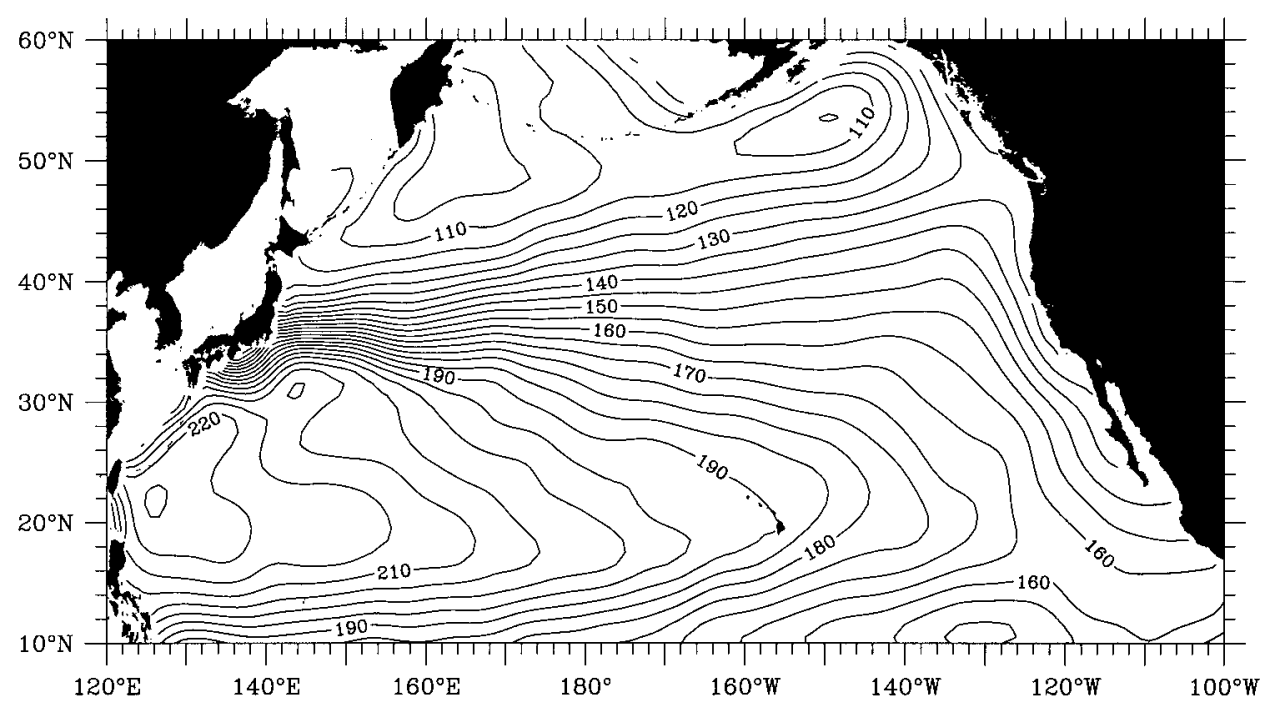

(b) Areas defining the current systems

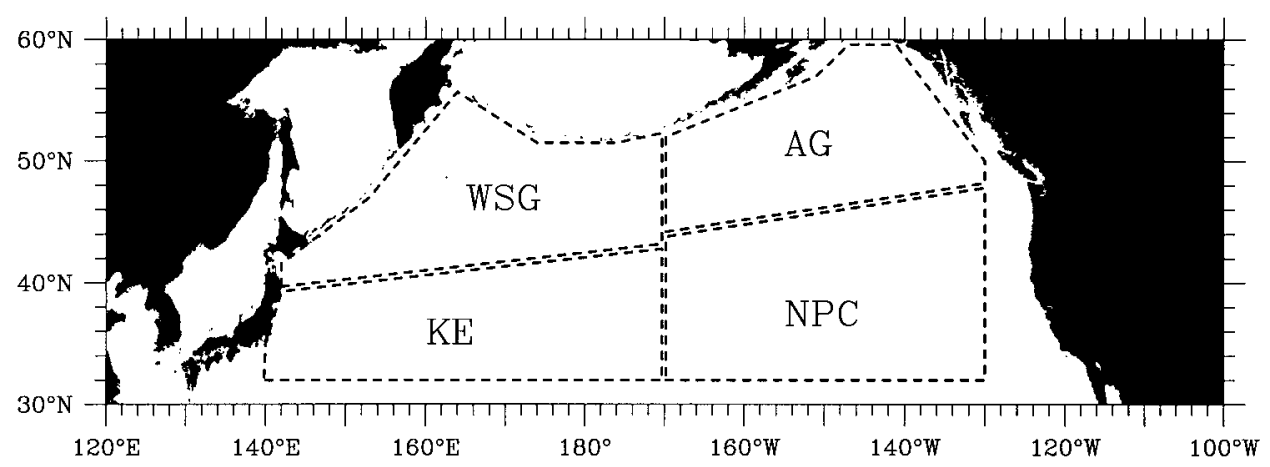

FIG. 1. (a) Surface dynamic topography $(\mathrm{cm})$ relative to $1000 \mathrm{dbar}$ calculated from the Levitus and Boyer (1994) and Levitus et al. (1994) climatology. (b) Areas defining the four current systems: the Kuroshio Extension (KE), the North Pacific Current (NPC), the Alaska Gyre (AG), and the Western Subarctic Gyre (WSG).

investigations that examine the individual current systems as entities and explore their interconnections have been lacking. This is primarily due to the vast geographical extent of each current system. The launch of the TOPEX/Poseidon (T/P) satellite in 1992 and its successful multiyear measurements of the sea surface height now provide a means to study the variability of gyre-scale ocean circulations. Using the T/P sea surface height (SSH) data of the past eight years, the first objective of this study is to quantify the large-scale changes in the four current systems of the midlatitude subtropical and subpolar North Pacific. Note that the subpolar North Pacific is where large-amplitude high-frequency SSH variability (wave periods shorter than a few months) is detected by the T/P observations. The high-frequency SSH signals and their connections to the surface wind forcing have been the subject of several recent studies (e.g., Fu and Davidson 1995; Fukumori et al. 1998). In this study, we will instead focus on the SSH signals that have timescales longer than $O(100$ days). It is worth emphasizing that the longer time series of the T/P SSH data allows us to not only document the low-frequency changes in a particular geographical domain, but also to test hypotheses and explore the underlying dynamics of the observed circulation changes. Indeed, the major part of this study is devoted to pursuing this second objective.

Being the outflow of an inertial western boundary current, the Kuroshio Extension is likely governed by different dynamics than the NPC, the Alaska gyre, and the WSG. In this study, we will focus on these latter three current systems, whose large-scale changes are expected to be externally forced and governed by linear dynamics. Despite the expected linear dynamics, there 
(a) $Q_{\text {net }}$ induced $\mathrm{rms}$ steric height variability $(\mathrm{cm})$

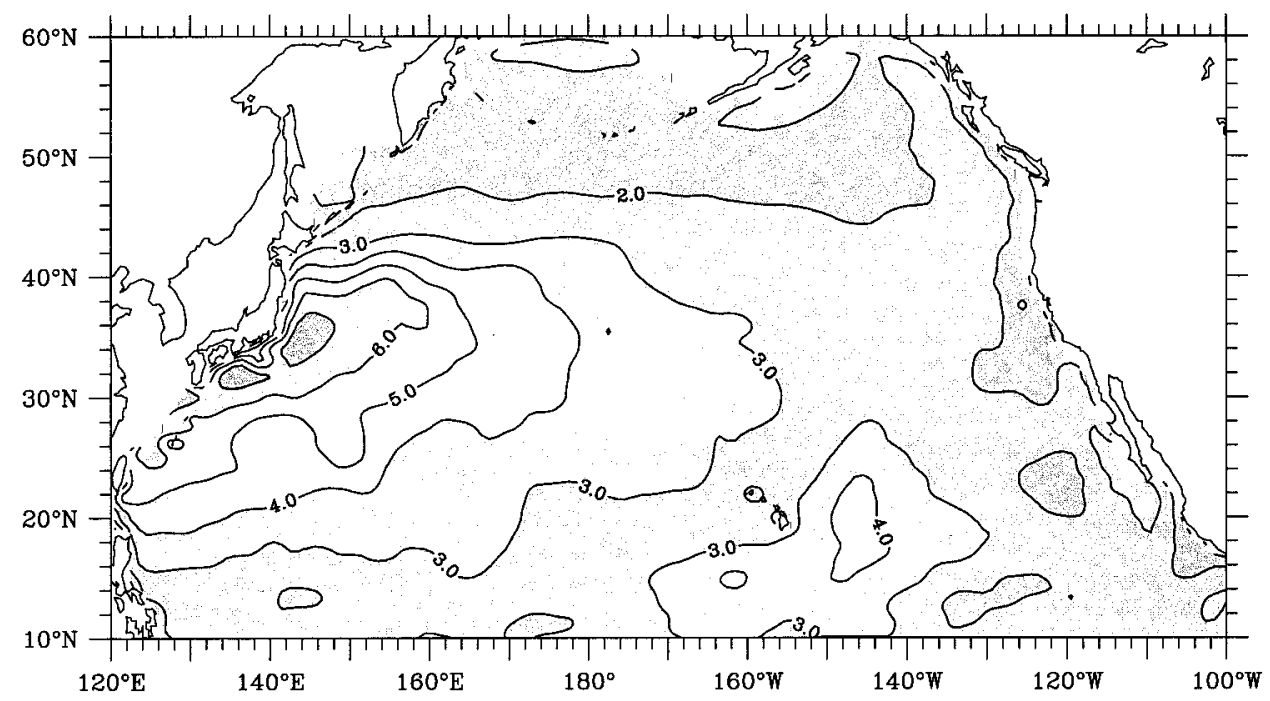

(b) E-P induced rms steric height variability $(\mathrm{cm})$

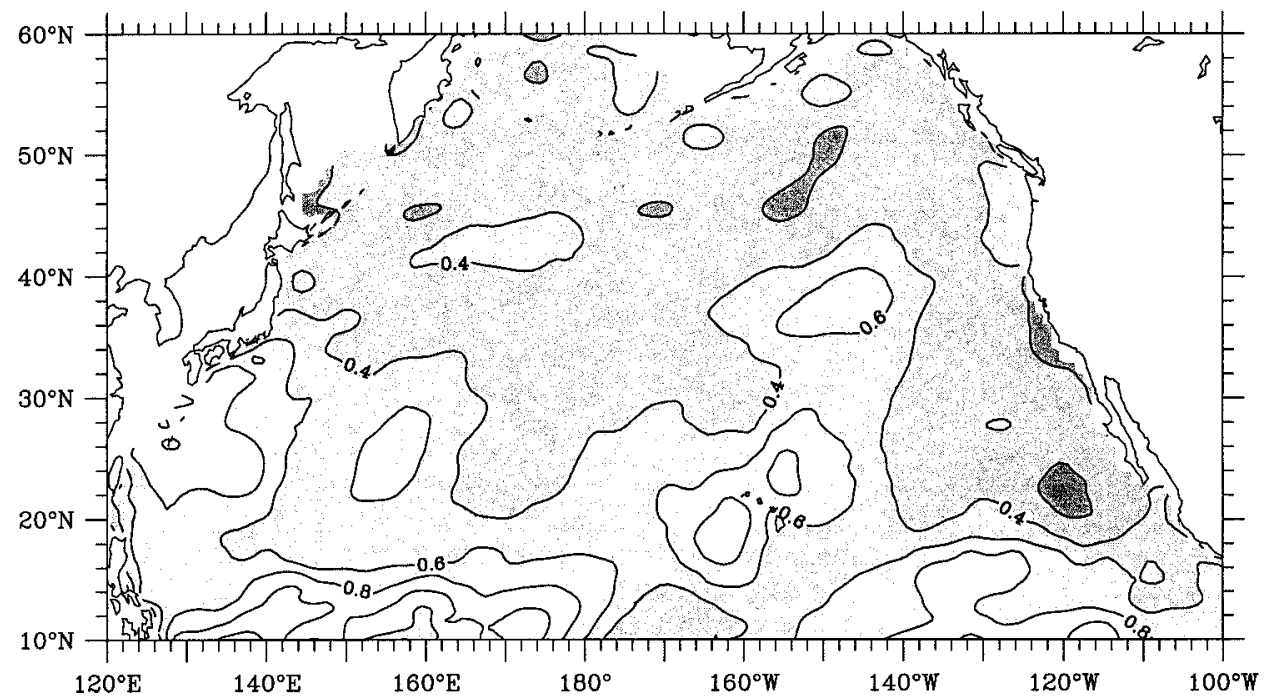

FIG. 2. Distributions of the rms steric height variability due to (a) net surface heat flux forcing and (b) evaporation minus precipitation $(E-P)$ forcing. Units in centimeters. Calculated from the daily net surface heat flux and $E-P$ data of the NCEP reanalysis for the T/P period of Oct 1992-Jul 2000.

remain questions and hypotheses that are not yet fully answered and tested against observations. For example, does the SSH variability in a midlatitude subtropical and subpolar ocean simply reflect changes in Ekman flux convergence/divergence? How important are baroclinic adjustment processes for the SSH changes in a subpolar ocean? Given the slow propagation of midlatitude baroclinic Rossby waves, what role does eddy dissipation play in determining the midlatitude SSH signals? In addition to these questions that are general to the SSH changes in any midlatitude ocean, there are also questions that are specific to the midlatitude North
Pacific Ocean. For example, are the SSH changes generated in the eastern tropical Pacific important for the variability in the Alaska gyre? In the western subarctic gyre, are the changes in the western boundary currents, the EKC and the Oyashio, in balance with the timedependent interior Sverdrup flow? Our goal is to address these questions under a simple and unified dynamic framework.

Several recent studies have examined long-term sea surface temperature (SST) data in the Pacific Ocean (e.g., Miller et al. 1994; Deser and Blackmon 1995; Nakamura et al. 1997). A common feature revealed by 
these analyses is that the dominant mode of the SST anomalies that has decadal timescales in the North $\mathrm{Pa}$ cific has its center of action located in the KuroshioOyashio extension region (i.e., along the boundary between the areas KE and WSG defined in Fig. 1b). As will become clear from this study, this is the region where significant, low-frequency ocean circulation changes are detected. Clarifying the dynamics governing the observed low-frequency SSH signals in the midlatitude North Pacific is, thus, also a needed step in improving our understanding of the ocean's role in determining the observed midlatitude SST anomalies.

This paper is organized as follows. Section 2 gives a brief description of T/P SSH data processing with an emphasis on the removal of steric height signals. In section 3 , we introduce a measure that quantifies the large-scale circulation fluctuations and describe the overall changes observed in the midlatitude North $\mathrm{Pa}-$ cific Ocean. With the aid of a two-layer dynamic model, detailed examinations into the causes of the observed changes in the North Pacific Current, the Alaska gyre, and the western subarctic gyre are presented in sections 4,5 , and 6 , respectively. Section 7, summarizes the results from this study.

\section{T/P altimeter data}

TOPEX/Poseidon altimeter data from the period of October 1992 through July 2000 (repeat cycles 2-287) are used in this study. For all the ground tracks passing the North Pacific Ocean, we first adjust the raw altimeter data for various environmental corrections, including the dry troposphere, the tides, and the inverse barometer effect, according to the GDR users handbook (Callahan 1993). After these corrections, the height data are interpolated to a common latitude grid with a one-persecond sample rate (about $5.6 \mathrm{~km}$ along a ground track). The alongtrack anomalous SSH profiles are then calculated by subtracting from each height profile the temporally averaged profile (namely, the geoid plus the 8yr mean SSH). Finally, a low-pass filter, which has a half-power point at $26 \mathrm{~km}$, is applied to the anomalous SSH data to suppress small-scale noise.

As recognized by several recent studies, a significant part of the altimetrically measured SSH anomaly signals in the midlatitude oceans is due to the seasonally varying surface heat flux and evaporation minus precipitation $(E-P)$ forcing that causes expansion or contraction of the water column (e.g., Wang and Koblinsky 1996; Stammer 1997; Gilson et al. 1998; Vivier et al. 1999). These so-called steric height anomalies are largely confined to the seasonal thermocline of the upper ocean. Because the steric height change does not alter the mass of seawater, it is dynamically passive and is not of interest to this study. To remove the steric height signals $\left(h_{s}^{\prime}\right)$, we estimate their time series along the T/ $P$ ground tracks by using the daily net surface heat flux and $E-P$ data from the National Centers for Envi- ronmental Prediction (NCEP) reanalysis (Kalnay et al. 1996). Specifically,

$$
\frac{\partial h_{s}^{\prime}}{\partial t}=\frac{\alpha(t)}{\rho_{o} c_{p}}[Q(t)-\overline{Q(t)}]-\beta(t) S_{o}(t)[F(t)-\overline{F(t)}],
$$

where $\rho_{o}, c_{p}, \alpha, \beta$, and $S_{o}$ are the reference density, the specific heat, the thermal expansion rate, the saline contraction rate, and the surface mixed layer salinity of seawater, respectively. In Eq. (1), $Q(t)$ denotes the net surface heat flux, $F(t)$ the $E-P$ rate, and overbars the temporal average. To find $\alpha(t), \beta(t)$, and $S_{o}(t)$, we used the monthly mixed layer temperature and salinity data of Levitus and Boyer (1994) and Levitus et al. (1994).

In Figs. $2 a$ and $2 b$, we plot the rms steric height variability associated with (a) the net surface heat flux forcing and (b) the $E-P$ forcing, respectively. Notice that the thermosteric height changes are dominated by annual variations and their rms amplitudes range from 2.0 to $7.0 \mathrm{~cm}$ (Fig. 2a). Due to the dominance of the annual variations, the spatial pattern of the thermosteric height signals reflects that of the seasonally varying net surface heat fluxes. Compared to the thermosteric height signals, the halosteric height signals have, in general, much smaller amplitudes (Fig. 2b). Aside from a localized area centered around $36^{\circ} \mathrm{N}, 150^{\circ} \mathrm{W}$ where the amplitude exceeds $0.6 \mathrm{~cm}$, the overall $\mathrm{rms}$ amplitude of the saline $h_{s}^{\prime}$ signals is less than $0.4 \mathrm{~cm}$ in the region north of $35^{\circ} \mathrm{N}$. That the thermosteric height changes dominate the total steric height signals is also found by Gill and Niiler (1973) and Vivier et al. (1999).

It is worth pointing out that over the shallow continental shelf regions along the Alaska/Canada coast, halosteric height signals have been observed to surpass the thermosteric height signals as a result of coastal runoff (Royer 1979, 1981; Tabata et al. 1986). The dominance of the saline signals, however, diminishes offshore of the continental slope (Tabata et al. 1986). Because the T/P SSH measurements are not adequately accurate over the shallow shelf regions, our analysis is confined to the offshore, open oceans (with water depth $>1 \mathrm{~km}$; see the shaded areas in Fig. 2), where the thermosteric height signals dominate $\left(h_{s}^{\prime}\right)$.

The strong spatial dependence of $\left(h_{s}^{\prime}\right)$, shown in Fig. $2 \mathrm{a}$, indicates that the steric height signals cannot be eliminated by simply removing the basin-averaged SSH anomalies from the individual T/P cycles (e.g., Isoguchi et al. 1997). By so doing, one would introduce spatially varying, spurious annual variations to the resultant SSH signals, rendering dynamic interpretations of these signals questionable. For data analyses throughout this study, the SSH anomalies $\left(h^{\prime}\right)$ are defined as the T/Pmeasured SSH anomalies minus the thermal plus saline steric height anomalies. In addition, $h^{\prime}$ signals with periods shorter than 70 days are removed in order to focus on the large-scale, low-frequency variability of the ocean circulation. 
(a) Relative intensity of the Western Subarctic Gyre

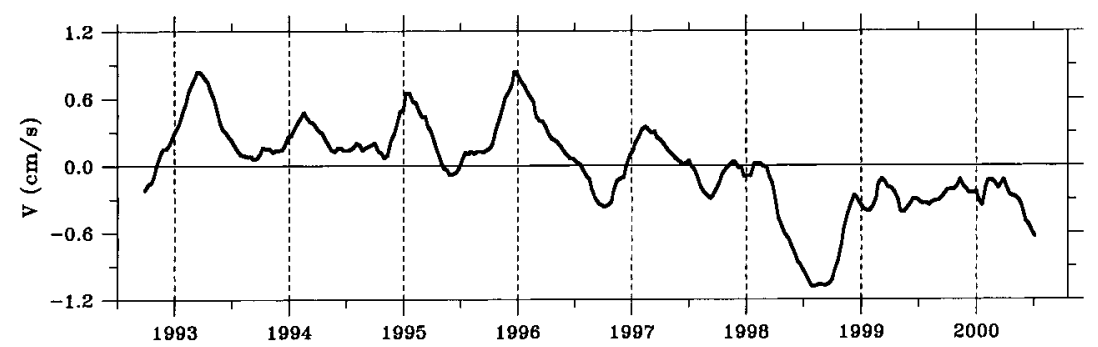

(b) Relative intensity of the Alaska Gyre

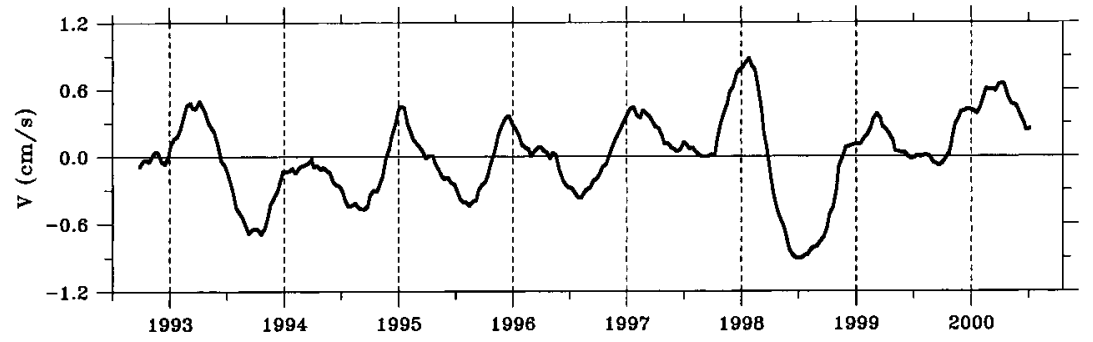

(c) Relative intensity of the North Pacific Current

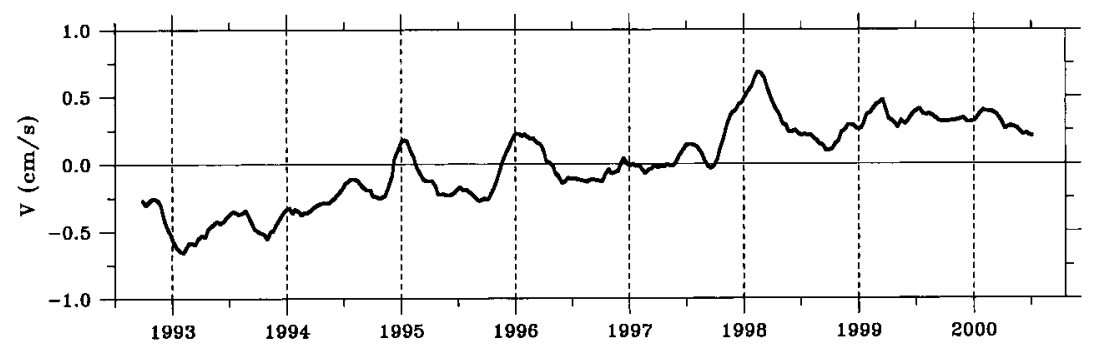

(d) Relative intensity of the Kuroshio Extension

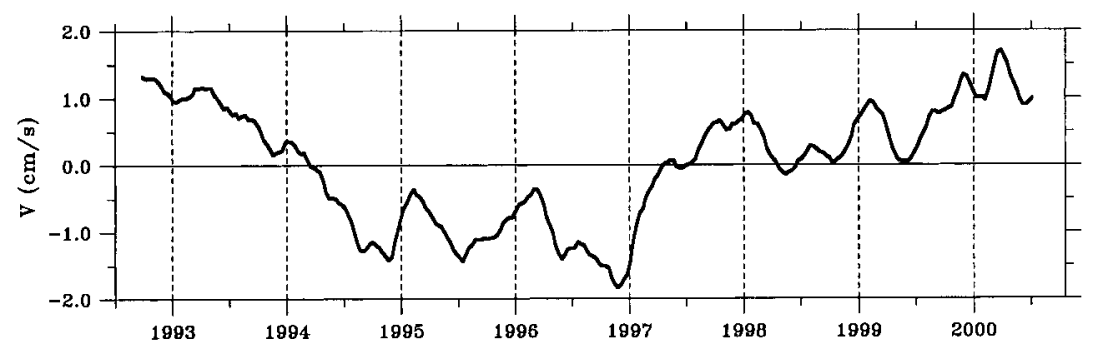

FIG. 3. "Relative intensity" of (a) the Western Subarctic Gyre, (b) the Alaska Gyre, (c) the Western Subarctic Gyre, and (d) the Kuroshio Extension. Here, the intensity is computed by first projecting the residual geostrophic flows (inferred from the T/P data) onto the Levitus climatological surface geostrophic streamlines, and then by averaging the projected residual geostrophic flows in the specified geographic area (see Fig. 1b).

\section{Changes in the midlatitude North Pacific current systems}

In this section, we describe the overall changes in the four current systems in the midlatitude North Pacific, namely, the western subarctic gyre, the Alaska gyre, the North Pacific Current, and the Kuroshio Extension. More detailed analyses examining the causes for these changes will be pursued in the ensuing sections. To quantify the large-scale changes of a current system measured by the T/P altimeters, we adopt in this section the following measure. Assuming geostrophy, the anomalous surface geostrophic velocity is related to $h^{\prime}$ by

$$
\mathbf{u}_{g}^{\prime}=\frac{g}{f} \mathbf{k} \times \nabla h^{\prime}
$$



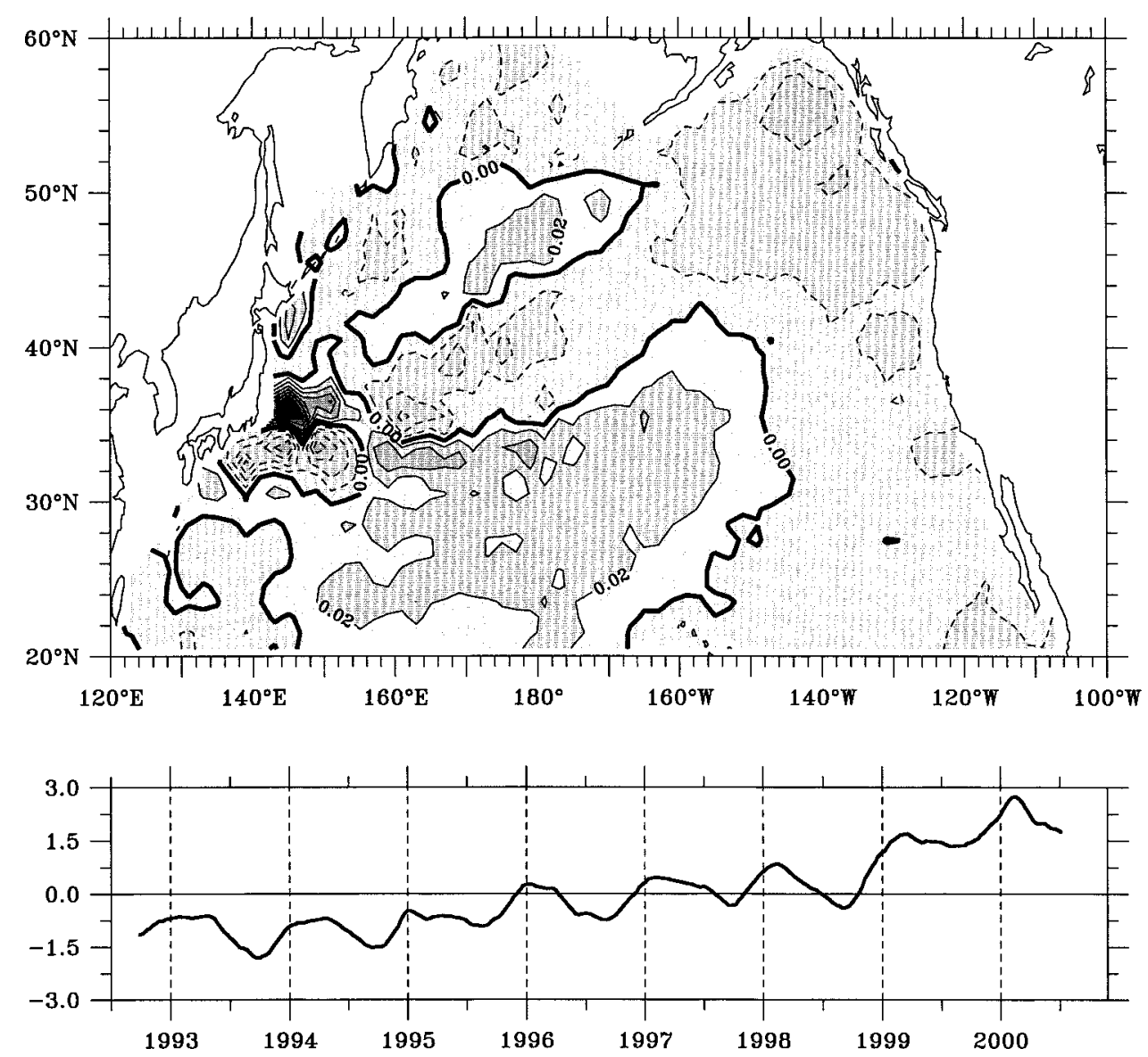

FIG. 4. First EOF mode of the T/P-measured SSH anomalies in the subtropical and subpolar North Pacific: the spatial pattern (top) and the corresponding weighting function (bottom). Units in meters. The steric height signals were removed prior to the EOF analysis. This mode explains $14.6 \%$ of the total variance.

where $\mathbf{k}$ is a unit vector in the vertical direction, $f$ is the Coliolis parameter, and $g$ is the gravity constant. Let

$$
\overline{\mathbf{u}}_{g}=\frac{g}{f} \mathbf{k} \times \nabla \bar{h}
$$

be the mean surface geostrophic velocity with $\bar{h}$ calculated from the Levitus climatology (Fig. 1a). Then, the area-averaged projection of the anomalous surface geostrophic flow along the mean surface geostrophic streamlines,

$$
V^{\prime}(t)=\frac{1}{A} \iint_{A} \mathbf{u}_{g}^{\prime}(t) \cdot \frac{\overline{\mathbf{u}}_{g}}{\left|\overline{\mathbf{u}}_{g}\right|} d x d y,
$$

provides one measure for the current intensity changes in the area. In Eq. (4), $A$ denotes the area of averaging. This measure, which we will term "relative intensity," is appropriate when circulation anomalies are aligned with the mean circulation, and proved to be a good measure of the true relative intensities of the NPC, the Alaska gyre, and the Kuroshio Extension. However, when a gyre undergoes structural changes, as was the case with the WSG during the study period, the projections of the anomalies on the mean do not reflect the true changes in intensity, and the usefulness of $V^{\prime}(t)$ defined by Eq. (4) diminishes (see section 6).

Figure 3 shows the time series of $V^{\prime}$ for the four current systems in the midlatitude North Pacific (see Fig. 1b for the geographical areas defining the current systems). Both the WSG and the Alaska gyre in Figs. $3 a$ and $3 b$ show clear annual variations with a maximum in January-March and a minimum in August-October. On average, the seasonal, peak-to-peak $V^{\prime}$ difference is about $0.8 \mathrm{~cm} \mathrm{~s}^{-1}$ for both the WSG and the Alaska gyre. With an average radius of $R=1000 \mathrm{~km}$ for the WSG ( $R=700 \mathrm{~km}$ for the Alaska gyre) and assuming that the anomalous surface geostrophic flow extends to a characteristic depth of $H_{o}=1000 \mathrm{~m}\left(H_{o}=500 \mathrm{~m}\right)$, $\Delta V^{\prime}=0.8 \mathrm{~cm} \mathrm{~s}^{-1}$ translates to a seasonal, peak-to-peak volume transport change $R H_{o} \Delta V^{\prime}$ of $\sim 8.0 \mathrm{~Sv}$ for the WSG and $\sim 2.8 \mathrm{~Sv}$ for the Alaska gyre, respectively ( $\mathrm{Sv}$ $\equiv 10^{6} \mathrm{~m}^{3} \mathrm{~s}^{-1}$ ). These transport numbers clearly depend on the chosen values of $R$ and $H_{o}$; nevertheless, the 2.8 $\mathrm{Sv}$ value for the Alaska gyre is close to the observed, 
SSH difference of 1997/98/99 minus 1993/94/95

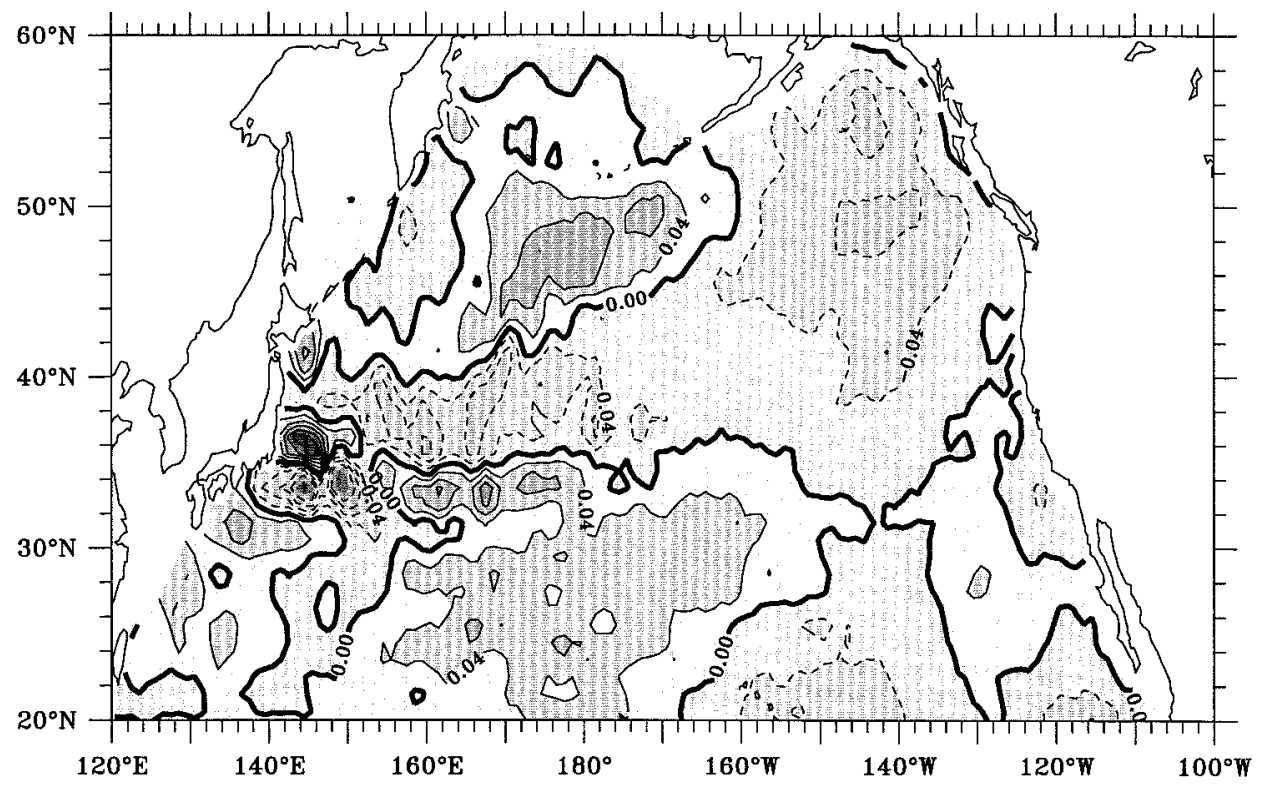

FIG. 5. SSH difference between the two triads: 1997/98/99 and 1993/94/95. Units in meters. Solid contours indicate positive SSH values and dashed lines, negative values.

peak-to-peak transport changes of the Alaskan Stream (2.4 Sv: Royer 1981). The 8.0 Sv value for the WSG is smaller than the seasonal transport changes found in the Oyashio southeast of Hokkaido ( $20 \mathrm{~Sv}$ : Kono and Kawasaki 1997). This could be due to the chosen characteristic depth $\left(H_{o}=1000 \mathrm{~m}\right)$ being too shallow for the WSG.

Figures $3 \mathrm{a}$ and $3 \mathrm{~b}$ also reveal interannual changes in the WSG and the Alaska gyre. With the exception of 1993 and 1998, the Alaska gyre shows a weak, but generally increasing, trend in its intensity. The WSG, on the other hand, appears to have a different interannual signal: it was relatively strong in 1993-96, weakened in 1997, and remained in a weakened state after 1998. As will become clear in section 6 , this low-frequency signal only signifies the interannual changes of the southern limb of the WSG (i.e., the Subarctic Current) and does not represent the intensity of the entire WSG.

The interannual changes are most clearly seen in the North Pacific Current (Fig. 3c). The steady intensification of the NPC from 1993 to 1998 has a $\Delta V^{\prime}$ of about $1 \mathrm{~cm} \mathrm{~s}^{-1}$. With a mean width of $1000 \mathrm{~km}$ and assuming $H_{o}=500 \mathrm{~m}$, this $\Delta V^{\prime}$ value translates to a $5 \mathrm{~Sv}$ volume transport increase in the NPC. The intensifying trend of the NPC appears to be leveling off following 1998. Notice that the NPC has a much weaker annual variation than the two subpolar gyres we noted above.

Interannual variability of the Kuroshio Extension exhibits a quite different characteristic (Fig. 3d). The Kuroshio Extension weakened gradually from late 1992 to 1995-96 and reversed the weakening trend after 1997.
These interannual changes are shown by Qiu (1995, 2000) to reflect the oscillation between the Kuroshio Extension's elongated mode and its contracted mode. In the elongated mode, the Kuroshio Extension has a larger eastward surface transport (which corresponds to a greater $V^{\prime}$ value in Fig. 3d), a more northerly axis position, and is associated with a more intense southern recirculation gyre. The reverse is true when the Kuroshio Extension is in the contracted mode. In comparison with the Kuroshio Extension system, our understanding of the dynamics controlling the low-frequency variability in the WSG, the Alaska gyre, and the NPC is more limited. In the following sections, we will focus our attention on these three current systems individually.

\section{The North Pacific Current}

The North Pacific Current variability is characterized by a persistent interannual trend. It is instructive here to examine this trend from a different perspective. To do so, we conducted an empirical orthogonal function (EOF) analysis of the SSH anomaly data in the region north of $20^{\circ} \mathrm{N}$. The first EOF mode explains $14.6 \%$ of the total variance, and its spatial pattern and weighting coefficient are shown in Fig. 4. The weighting coefficient of this mode is dominated by a linear increasing trend with seasonal modulations embedded. In the NPC region of the eastern North Pacific $\left(32^{\circ}-45^{\circ} \mathrm{N}\right)$, the sign of the spatial pattern is negative to the north and positive to the south, suggesting that the zonal-mean meridional SSH gradient across the NPC increased steadily over 
the T/P period. The robustness of the spatial pattern of this EOF mode can be verified if we simply take the SSH difference between the three years in the beginning of the T/P mission, 1993/94/95, and the more recent three years of 1997/98/99. The SSH pattern from this simple subtraction (see Fig. 5) resembles very much the spatial pattern of the first EOF mode and signifies again the enhancement of the north-south SSH gradient across the NPC.

To quantify the interannual changes in the NPC, we plot in Figs. $6 \mathrm{a}$ and $6 \mathrm{~b}$ the time series of the SSH anomalies averaged in a box north and south of the NPC $\left(h_{N}^{\prime}\right.$ and $\left.h_{S}^{\prime}\right)$, respectively. Taking their difference and multiplying it by $-g / f W$, where $W$ is the meridional distance between the two boxes, gives a measure for the zonal-mean surface flow of the NPC. The NPC's relative intensity thus estimated (Fig. 6c) is very similar to that of Fig. 3c based on Eq. (4). Given the zonality of the NPC, this similarity is expected. There are two points worth noticing from Fig. 6. First, both $h_{N}^{\prime}$ and $h_{S}^{\prime}$ have similar annual variations. This explains the weak annual signals in the NPC. Second, the interannual trend in the NPC's intensity is mainly due to the gradual SSH drop on the northern side of the NPC. As such, understanding the interannual changes of the NPC requires clarifying the causes that determine the SSH signals on the northern side of the NPC.

As a dynamic framework to examine the SSH variations, we adopt in this study a two-layer ocean model. Though simple in its formulation, the two-layer model captures the barotropic and first-mode baroclinic Rossby wave processes that are important for the large-scale $\mathrm{SSH}$ changes. In the two-layer model, linearized momentum and continuity equations are:

$$
\begin{aligned}
\frac{\partial \mathbf{u}_{1}}{\partial t}+f \mathbf{k} \times \mathbf{u}_{1} & =-g \boldsymbol{\nabla} h_{1}+\frac{\boldsymbol{\tau}}{\rho_{o} H_{1}}, \\
\frac{\partial}{\partial t}\left(h_{1}-h_{2}\right)+H_{1} \boldsymbol{\nabla} \cdot \mathbf{u}_{1} & =0, \\
\frac{\partial \mathbf{u}_{2}}{\partial t}+f \mathbf{k} \times \mathbf{u}_{2} & =-g \boldsymbol{\nabla} h_{1}-g^{\prime} \boldsymbol{\nabla} h_{2}, \\
\frac{\partial h_{2}}{\partial t}+H_{2} \boldsymbol{\nabla} \cdot \mathbf{u}_{2} & =0,
\end{aligned}
$$

where $\mathbf{u}_{i}$ is the $i$ th-layer velocity vector, $H_{i}$ is the mean thickness of the $i$ th-layer, $h_{1}$ is the SSH anomaly, $h_{2}$ is the layer interface anomaly, $\tau$ is the surface wind stress vector, $\rho_{o}$ is the reference density, and $g^{\prime}=\left(\rho_{2}-\rho_{1}\right) g$ / $\rho_{o}$ is the reduced gravity. For simplicity, we have taken $H_{2}=$ const in Eq. (8). Effects of bottom topography will be discussed toward the end of this section. Assuming that the timescales of interest are long compared with the inertial period, we can combine Eqs. (5)-(8) to form the following vorticity equations:

$$
\begin{array}{r}
\frac{\partial}{\partial t}\left[\nabla^{2} h_{1}-\frac{f_{o}^{2}}{g H_{1}}\left(h_{1}-h_{2}\right)\right]+\beta \frac{\partial h_{1}}{\partial x}=\frac{f_{o} \boldsymbol{\nabla} \times \boldsymbol{\tau}}{\rho_{o} g H_{1}}, \\
\frac{\partial}{\partial t}\left[\nabla^{2} h_{1}+\frac{g^{\prime}}{g} \nabla^{2} h_{2}-\frac{f_{o}^{2}}{g H_{2}} h_{2}\right]+\beta \frac{\partial h_{1}}{\partial x}+\frac{\beta g^{\prime}}{g} \frac{\partial h_{2}}{\partial x}=0,
\end{array}
$$

where $\beta$ is the meridional gradient of $f$ and $f_{o}$ is the Coriolis parameter at the reference latitude.

It is useful here to express the SSH anomaly as

$$
h_{1} \equiv h_{\mathrm{bc}}+h_{\mathrm{bc}}
$$

where $h_{\mathrm{bc}}$ denotes that part of the SSH change due to the baroclinic processes, and $h_{\mathrm{bt}}$ the part due to the barotropic processes. Equations governing $h_{\mathrm{bc}}$ and $h_{\mathrm{bt}}$ can be derived from Eqs. (9) and (10) as follows:

$$
\begin{aligned}
\frac{\partial}{\partial t}\left(\nabla^{2} h_{\mathrm{bc}}-\frac{f_{o}^{2}}{g^{\prime} H_{e}} h_{\mathrm{bc}}\right)+\beta \frac{\partial h_{\mathrm{bc}}}{\partial x} & =\frac{f_{o} H_{e} \boldsymbol{\nabla} \times \boldsymbol{\tau}}{\rho_{o} g H_{1}^{2}}, \\
\frac{\partial}{\partial t}\left(\nabla^{2} h_{\mathrm{bt}}\right)+\beta \frac{\partial h_{\mathrm{bt}}}{\partial x} & =\frac{f_{o} \boldsymbol{\nabla} \times \boldsymbol{\tau}}{\rho_{o} g\left(H_{1}+H_{2}\right)},
\end{aligned}
$$

where $H_{e}=H_{1} H_{2} /\left(H_{1}+H_{2}\right)$ denotes the equivalent depth in the two-layer model. Given that baroclinic Rossby radii of deformation in the region of our interest are shorter than $40 \mathrm{~km}$ (e.g., Chelton et al. 1998), the long-wave approximation is justified. Under this approximation, Eq. (12) simplifies to

$$
\frac{\partial h_{\mathrm{bc}}}{\partial t}-\frac{\beta g^{\prime} H_{e}}{f_{o}^{2}} \frac{\partial h_{\mathrm{bc}}}{\partial x}=-\frac{g^{\prime} H_{e}^{2} \boldsymbol{\nabla} \times \boldsymbol{\tau}}{\rho_{o} g f_{o} H_{1}^{2}} .
$$

Denoting $c_{R}=-\beta g^{\prime} H_{e} / f_{o}^{2}$, the solution to Eq. (14) can be found by integration along the long baroclinic Rossby wave characteristic:

$$
\begin{aligned}
h_{\mathrm{bc}}(x, t)= & h_{\mathrm{bc}}\left(x_{e}, t-\frac{x-x_{e}}{c_{R}}\right) \\
& -\frac{f_{o} H_{e}}{\rho_{o} g \beta H_{1}^{2}} \int_{x_{e}}^{x} \nabla \times \tau\left(x^{\prime}, t-\frac{x-x^{\prime}}{c_{R}}\right) d x^{\prime},
\end{aligned}
$$

where $x_{e}$ is the longitudinal location of the eastern boundary. Barotropic ocean responses to fluctuating surface winds are timescale dependent. For timescales longer than months, Willebrand et al. (1980) show that the time derivative term in the barotropic vorticity equation is negligible and that Eq. (13) in this case reduces to the time-dependent Sverdrup balance:

$$
\frac{\partial h_{\mathrm{bt}}}{\partial x}=\frac{f_{o} \boldsymbol{\nabla} \times \boldsymbol{\tau}}{\rho_{o} g \beta\left(H_{1}+H_{2}\right)} .
$$

Estimating $h_{\mathrm{bt}}$ and $h_{\mathrm{bc}}$ from Eqs. (16) and (15) requires the $\boldsymbol{\nabla} \times \boldsymbol{\tau}$ field. In this study, we use the monthly wind 

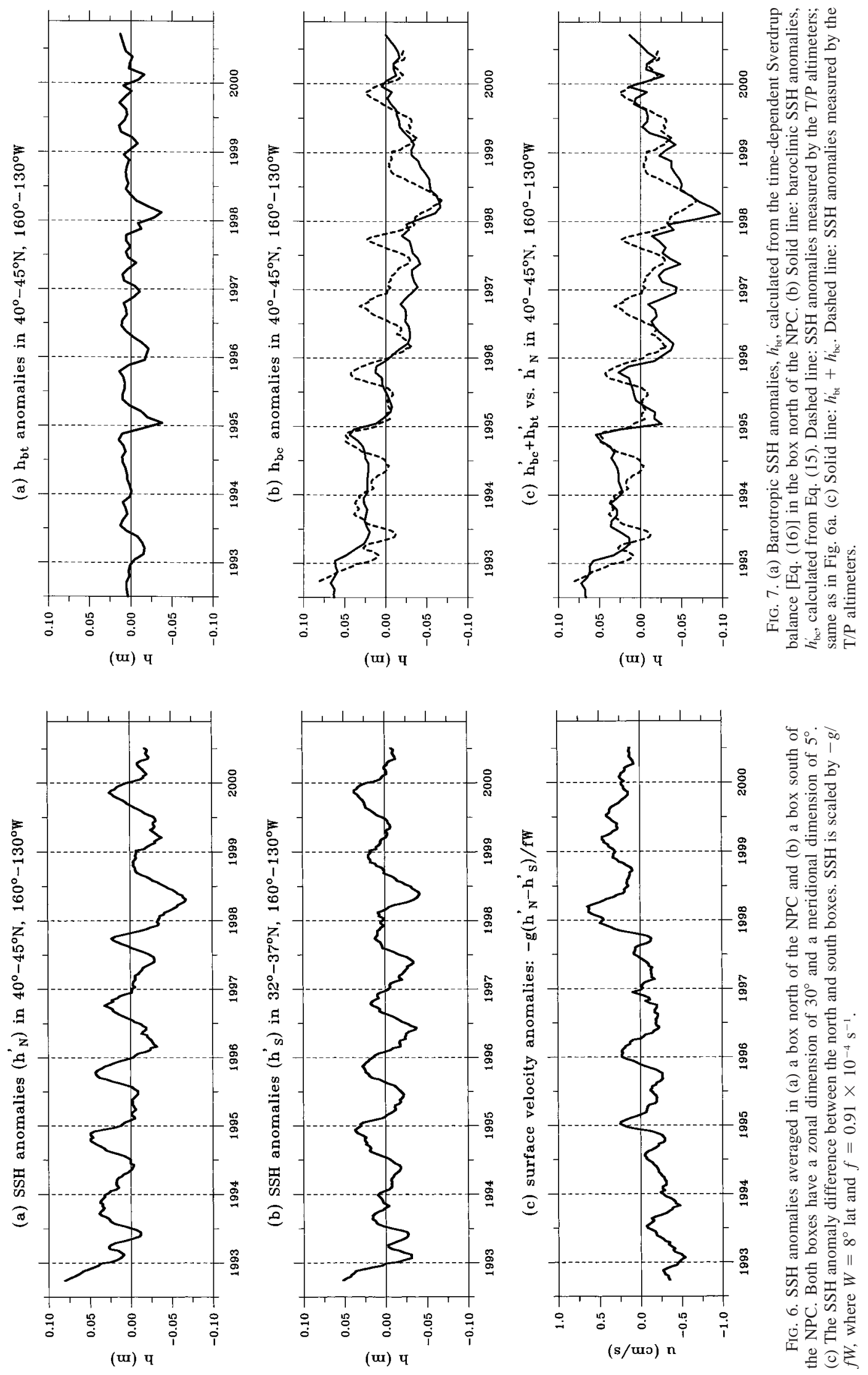


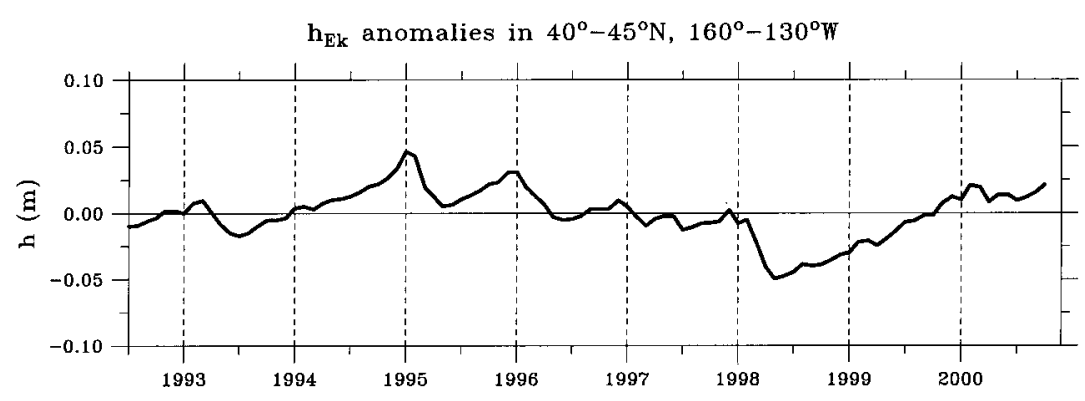

FIG. 8. SSH anomalies due to anomalous Ekman pumping [Eq. (17)] in the box north of the NPC.

stress dataset from the NCEP reanalysis (Kalnay et al. 1996). The horizontal resolution of the NCEP data is $1.904^{\circ}$ lat $\times 1.825^{\circ}$ long. In Fig. 7a, we plot the time series of the $h_{\mathrm{bt}}$ anomalies in the region north of the NPC $\left(40^{\circ}-45^{\circ} \mathrm{N}, 160^{\circ}-130^{\circ} \mathrm{W}\right)$ computed from Eq. (16). In accordance with the theory of Willebrand et al. (1980), wind stress curl signals shorter than two months have been removed. Also, $H_{1}+H_{2}=5000 \mathrm{~m}$ is assumed. Figure 7a shows that the barotropic SSH changes in this region are commonly small, $O(2 \mathrm{~cm})$, except during wintertime when the Aleutian low intensifies and extends eastward over the subpolar North Pacific Ocean (Rienecker and Ehret 1988; Strub and James 2000a, manuscript submitted to Progress in Oceanography, hereafter SJa). Although the $h_{\mathrm{bt}}$ anomalies show significant winter-to-winter changes, the overall interannual signal in $h_{\mathrm{bt}}^{\prime}$ is of a different nature from that detected in the T/P data (Fig. 6a).

To estimate the baroclinic SSH anomalies using Eq. (15), we adopt the following parameter values: $g^{\prime}=$ $0.03 \mathrm{~m} \mathrm{~s}^{-2}$ (White 1982) and $H_{1}+H_{2}=5000 \mathrm{~m}$. For the long baroclinic Rossby wave speed $c_{R}$, we use the latitude-dependent values presented in Killworth et al. (1997). Along $42.5^{\circ} \mathrm{N}$, for example, $c_{R}=-1.3 \mathrm{~cm} \mathrm{~s}^{-1}$. By requiring the long baroclinic Rossby wave speed, $c_{R}$ $=-\beta g^{\prime} H_{1} H_{2} f_{o}^{2} /\left(H_{1}+H_{2}\right)$ to match the theoretical value of Killworth et al., we obtain $H_{1}=264 \mathrm{~m}$ and $H_{e}$ $=250 \mathrm{~m}$ for the region north of the NPC. The solid line in Fig. 7b shows the time series of the $h_{\mathrm{bc}}$ anomalies based on these parameter values. Compared to the T/Pderived SSH signals ( $h_{N}^{\prime}$, the dashed line), the baroclinic SSH anomalies capture well the two observed interannual trends, namely, the steady SSH drop from late 1992 to 1998 and the reversing trend following 1998. The predictive skill of $h_{N}^{\prime}$ by $h_{\mathrm{bc}}^{\prime}$ in Fig. $7 \mathrm{~b}$ is $S=0.50 .{ }^{1}$ Notice that while adding the barotropic SSH signals to $h_{\mathrm{bc}}^{\prime}$ improves the comparison with the observed $\mathrm{SSH}$ signals on the annual timescale (see Fig. 7c), it is the baroclinic SSH changes that determine the interannual signal in $h_{N}^{\prime}$.

\footnotetext{
${ }^{1}$ Here, predictive skill is defined by $S=1-\left\langle\left(h_{o}-h_{p}\right)^{2}\right\rangle /\left\langle h_{o}^{2}\right\rangle$, where $h_{o}$ is the observed signal, $h_{p}$ is its prediction, and angle brackets denote time averaging.
}

Several investigators in the past have hypothesized that the SSH anomalies may simply reflect convergence/ divergence of the anomalous surface Ekman fluxes (e.g., Kelly et al. 1993; Bhaskaran et al. 1993; Lagerloef 1995). In other words, one may simplify the baroclinic vorticity equation (14) to

$$
\frac{\partial h_{\mathrm{Ek}}}{\partial t}=-\frac{g^{\prime} H_{e}^{2} \boldsymbol{\nabla} \times \boldsymbol{\tau}}{\rho_{o} g f_{o} H_{1}^{2}} .
$$

To test this hypothesis, we plot in Fig. 8 the time series of the $h_{\mathrm{Ek}}$ anomalies in the region north of the NPC using Eq. (17) and the parameter values specified above. Although $h_{\mathrm{Ek}}^{\prime}$ exhibits large interannual changes, it lacks the interannual trends that characterize the $h_{\mathrm{bc}}^{\prime}$ time series (Fig. 7b). In general, a difference between $h_{\mathrm{Ek}}^{\prime}$ and $h_{\mathrm{bc}}^{\prime}$ implies that the wind stress curl forcing in the past and over the region to the east of the domain of interest is important. Since the domain of our interest is located close to the eastern boundary, we expect that the steady $\mathrm{SSH}$ drop, which is predicted in $h_{\mathrm{bc}}^{\prime}$ for the T/P period but not in $h_{\mathrm{Ek}}^{\prime}$, is due to the wind stress curl forcing prior to October 1992. To verify this point, we plot in Fig. 9 the $\boldsymbol{\nabla} \times \boldsymbol{\tau}$ anomalies along $41.9^{\circ} \mathrm{N}$ as a function of time and longitude. The straight line in the figure indicates the phase speed of the long baroclinic Rossby wave at this latitude: $c_{R}=-1.43 \mathrm{~cm} \mathrm{~s}^{-1}$. Notice that the wind stress curl anomalies are persistently negative during the period from 1986 to 1990 . This long-lasting negative wind stress curl results in Ekman flux convergence and is the reason why the observed $\mathrm{SSH}$ anomalies at the beginning of the T/P mission were relatively high. From 1991 to 1998, Fig. 9 shows that the wind stress curl anomalies north of the NPC were largely positive. It is this decadal transition from $\boldsymbol{\nabla} \times \boldsymbol{\tau}^{\prime}<0$ in 1986-90 to $\boldsymbol{\nabla} \times \boldsymbol{\tau}^{\prime}>0$ in 1991-98 that causes the decreasing trend in $h_{\mathrm{bc}}^{\prime}$ shown in Fig. 7b. Notice that the wind stress curl anomalies after 1998 change the sign to negative; this transition from a positive to a negative wind stress curl forcing is responsible for the reversal in the $\mathrm{SSH}$ trend seen in $h_{N}^{\prime}$ and $h_{\mathrm{bc}}^{\prime}$ following 1998.

The lower layer thickness $H_{2}$ of our two-layer model has been assumed to be constant. In the limit of $H_{1} /\left(H_{1}\right.$ 


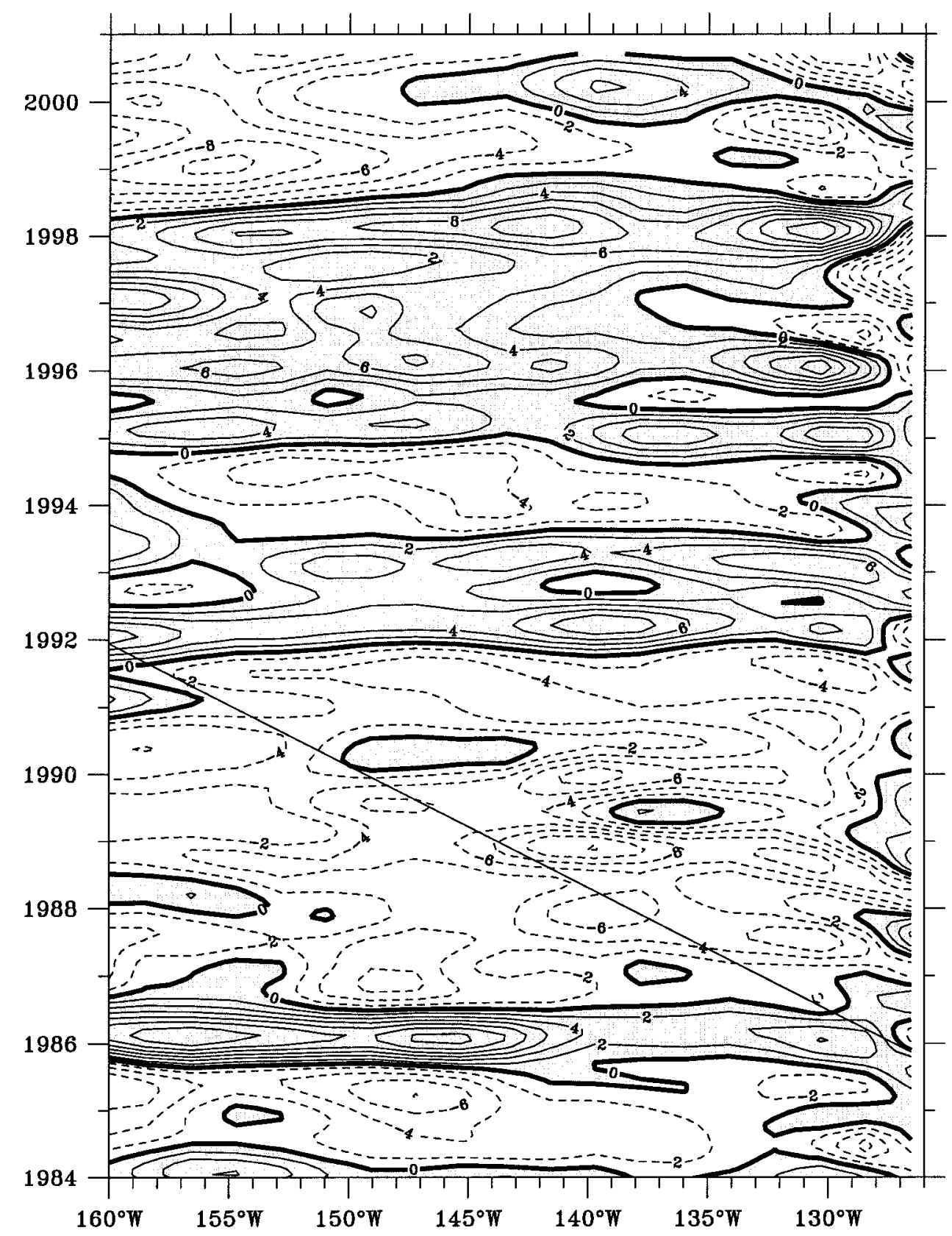

FIG. 9. Wind stress curl anomalies along $41.9^{\circ} \mathrm{N}$ as a function of time and longitude. Units in $10^{-8} \mathrm{~N} \mathrm{~m}^{-1}$. For clarity, signals with periods shorter than 6 months have been removed. The straight thin line denotes the characteristic of long baroclinic Rossby waves at this latitude $\left(c_{R}=-1.43 \mathrm{~cm} \mathrm{~s}^{-1}\right)$. The SSH signal at a point on this line is determined by the wind stress curl forcing accumulated along the characteristic to the east of the point.

$\left.+H_{2}\right) \ll 1,{ }^{2}$ a variable bottom topography will have little effect upon the baroclinic SSH changes governed by Eq. (14). Allowing a variable $H_{2}$, however, does alter

${ }^{2}$ Typical depth ratio for the midlatitude North Pacific Ocean is $\sim 0.05$. the barotropic vorticity equation. Specifically, the timedependent Sverdrup balance is now

$$
J\left(h_{\mathrm{bt}}, \frac{f}{H_{1}+H_{2}}\right)=\frac{f \boldsymbol{\nabla} \times \boldsymbol{\tau}}{\rho_{o} g\left(H_{1}+H_{2}\right)^{2}},
$$

where $J$ is the Jacobian operator. Instead of latitudinal 
lines, $h_{\mathrm{bt}}$ in Eq. (18) can again be evaluated by integration along constant $f /\left(H_{1}+H_{2}\right)$ contours emanating from the eastern boundary. Notice that the maps presented by Koblinsky et al. (1989, Plate 2) and Vivier et al. (1999, their Fig. 10) show that, except very close to the eastern boundary, large-scale $f /\left(H_{1}+H_{2}\right)$ contours in the NPC region do not deviate substantially from the latitudinal lines. Given the large spatial scales of the surface wind forcing, it is reasonable to expect that inclusion of the bottom topography in our two-layer model will not significantly change the $h_{\mathrm{bt}}^{\prime}$ time series presented in Fig. 7a.

For the region south of the NPC, solving Eq. (15) indicates that the baroclinic SSH variability there has an interannual amplitude much smaller than its counterpart to the north of the NPC. Because the interannual changes in the NPC are largely due to the SSH changes on the northern side of the NPC (Fig. 6), detailed results on $h_{S}^{\prime}$ will not be presented here. In concluding this section, we again emphasize the importance of the planetary vorticity advection term in Eq. (14). The baroclinic SSH signals are not determined by the Ekman flux convergence or divergence; instead, they represent the integrated outcome of the past wind stress curl forcing along baroclinic Rossby wave characteristics.

\section{The Alaska gyre}

In the Alaska gyre region north of $48^{\circ} \mathrm{N}$ and east of $165^{\circ} \mathrm{W}$, the first EOF mode of the observed SSH anomalies shows that the center of the Alaska gyre has shoaled steadily over the past eight years (Fig. 4). From geostrophy, this implies a strengthening trend in the cyclonic circulation of the Alaska gyre. The result presented in Fig. 3b, on the other hand, indicates that the intensity of the Alaska gyre has a more complicated interannual signal than a well-defined strengthening trend. To clarify this apparent discrepancy, we plot in Fig. 10 the SSH anomalies in a $2^{\circ}$ band along the Alaska/ Canada coast from $130^{\circ}$ to $165^{\circ} \mathrm{W}\left(h_{C}^{\prime}\right)$ and the SSH anomalies in the Alaska gyre offshore of this coastal band $\left(h_{o}^{\prime}\right)$. Consistent with the steady shoaling signal found in the EOF analysis, the $h_{o}^{\prime}$ time series in Fig. 10a shows a clear decreasing trend. The SSH anomalies in the coastal band reveal an interannual signal of a considerably different nature (Fig. 10b): $h_{C}^{\prime}$ was high in 1992/93 and in late 1997/early 1998, and dropped to a persistent low level after mid-1998. Not surprisingly, it is the difference between $h_{C}^{\prime}$ and $h_{O}^{\prime}$ that determines the intensity of the Alaska gyre (cf. Fig. 10c with Fig. 3b). In the following, we will try to clarify the forcing mechanisms underlying the $h_{O}^{\prime}$ and $h_{C}^{\prime}$ signals.

For the offshore Alaska gyre region, we plot in Figs. $11 \mathrm{a}$ and $11 \mathrm{~b}$ the barotropic and baroclinic SSH anomalies calculated from Eqs. (16) and (15), respectively. The results are in general similar to those discussed above for the NPC; namely, the barotropic SSH signals are dominated by the annual and intraannual variations, whereas the baroclinic SSH signals capture the interannual trend present in the $h_{O}^{\prime}$ time series (the dashed line in Fig. 11b). Examining the wind stress curl changes along $53.3^{\circ} \mathrm{N}$ across the center of the Alaska gyre (Fig. 12) reveals that the decreasing trend in $h_{\mathrm{bc}}^{\prime}$ is due to the fact that negative wind stress curl anomalies over the Alaska gyre in 1989-93 produced positive SSH anomalies in 1993, whereas the wind stress curl anomalies were largely positive following 1994 . This again demonstrates the importance of the wind stress curl forcing prior to the launch of the T/P satellite in contributing to the SSH trends detected during the T/P period.

Figure 11c shows the comparison between $h_{O}^{\prime}$ and the sum of the barotropic and baroclinic SSH signals. The high predictive skill of $h_{O}^{\prime}$ by $h_{\mathrm{bt}}^{\prime}+h_{\mathrm{bc}}^{\prime}(S=0.84)$ indicates that much of the observed, large-scale SSH signals in the offshore Alaska gyre can be explained by the barotropic and first-mode baroclinic Rossby wave dynamics. This favorable comparison reinforces the point we raised in section 3 of appropriately removing the steric height signals prior to analyzing the T/P SSH data. The dashed line in Fig. 13a shows the T/P SSH anomalies in the offshore Alaska gyre region without the removal of the steric height signal. Even though the steric height signal in this region is comparatively small (recall Fig. 2), failing to properly subtract it would nevertheless obscure the conclusion that the two-layer dynamics form an adequate basis for understanding the observed large-scale SSH anomalies.

On the annual timescale, Fig. 10c shows that the intensity of the Alaska gyre peaks in winter. This finding is consistent with the studies by Bhaskaran et al. (1993) using the Geosat altimeter data, and by SJa using the T/P altimeter data. As a possible cause for the winter maximum of the gyre intensity, Bhaskaran et al. suggested seasonal Ekman pumping, although no quantitative argument was provided in their study. To assess the effect of the Ekman pumping forcing, we plot in Fig. 13b the Ekman pumping-induced SSH anomalies calculated from Eq. (17). The seasonal peakto-peak amplitude in $h_{\mathrm{Ek}}^{\prime}$ is $\sim 2 \mathrm{~cm}$, which is less than half of the observed amplitude of $5 \mathrm{~cm}$ (Fig. 10a). Based on the result shown in Fig. 11, we believe that the annual modulation in the Alaska gyre intensity should be interpreted as the barotropic response to the seasonal wind stress curl forcing. The magnitude of this response is quantifiable by the time-dependent Sverdrup balance.

For the interannual changes in the Alaskan gyre intensity, Fig. 10 shows clearly the contribution from the SSH signal along the Alaska/Canada coast. That the alongshore SSH anomalies were high during late 1997/ early 1998 points to their connection to the tropical, ENSO-related SSH variability. Indeed, plotting the SSH anomalies along the eastern boundary of the North Pacific from the equator to $60^{\circ} \mathrm{N}$ and along the Alaska coast from $142^{\circ}$ to $165^{\circ} \mathrm{W}$ (Fig. 14) reveals the general 


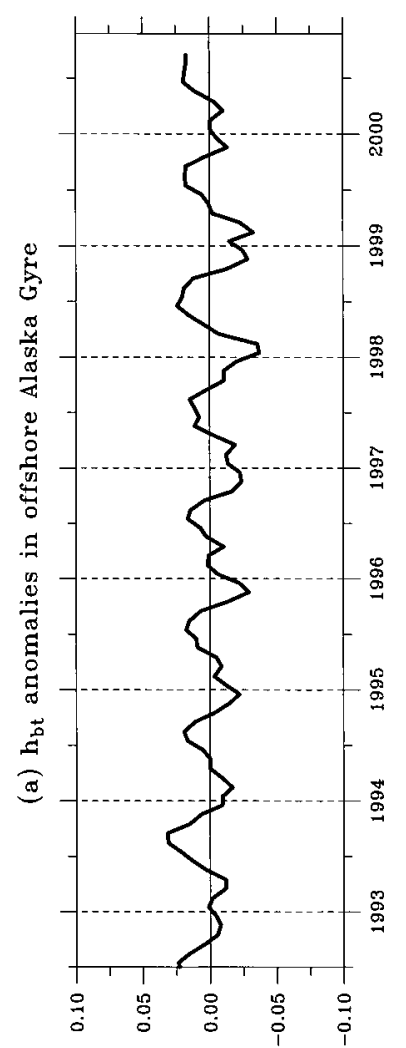

(ur) प

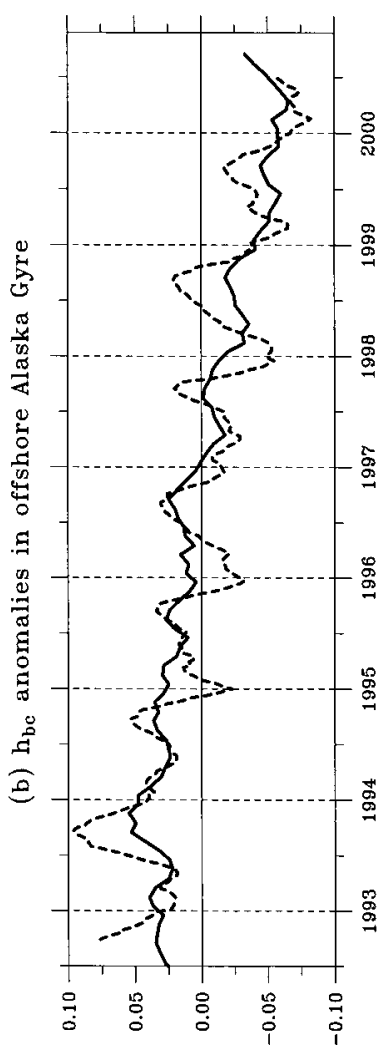

(ur) 4
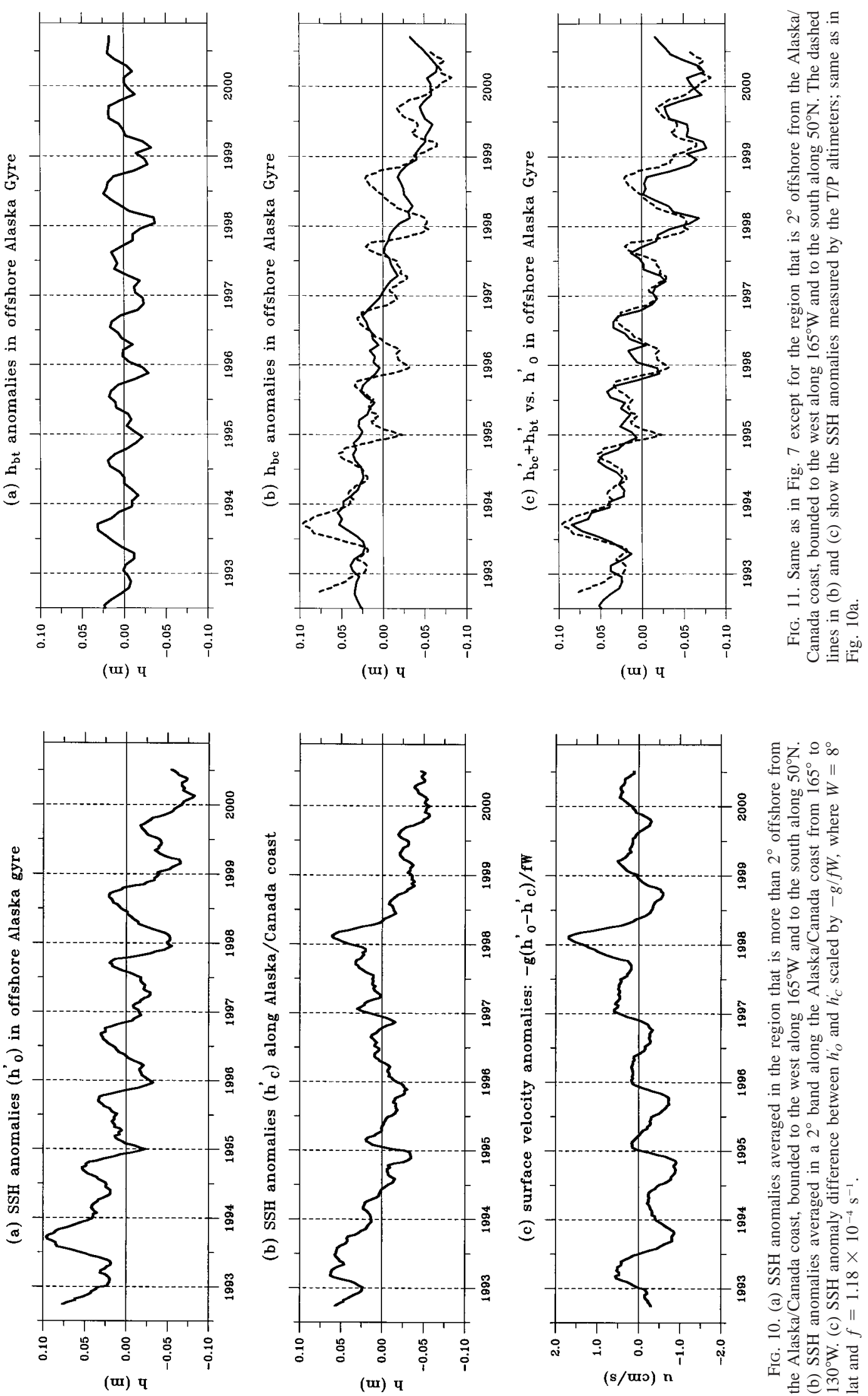

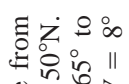

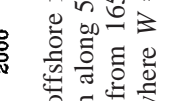

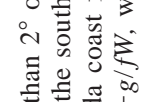
ت्ञ

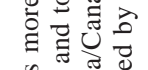
氜势

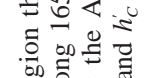

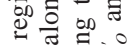

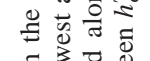
$\exists=\overline{0}$

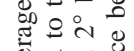

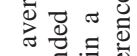

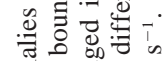
言荡焉苍 牙 ๙ 월 可

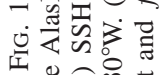




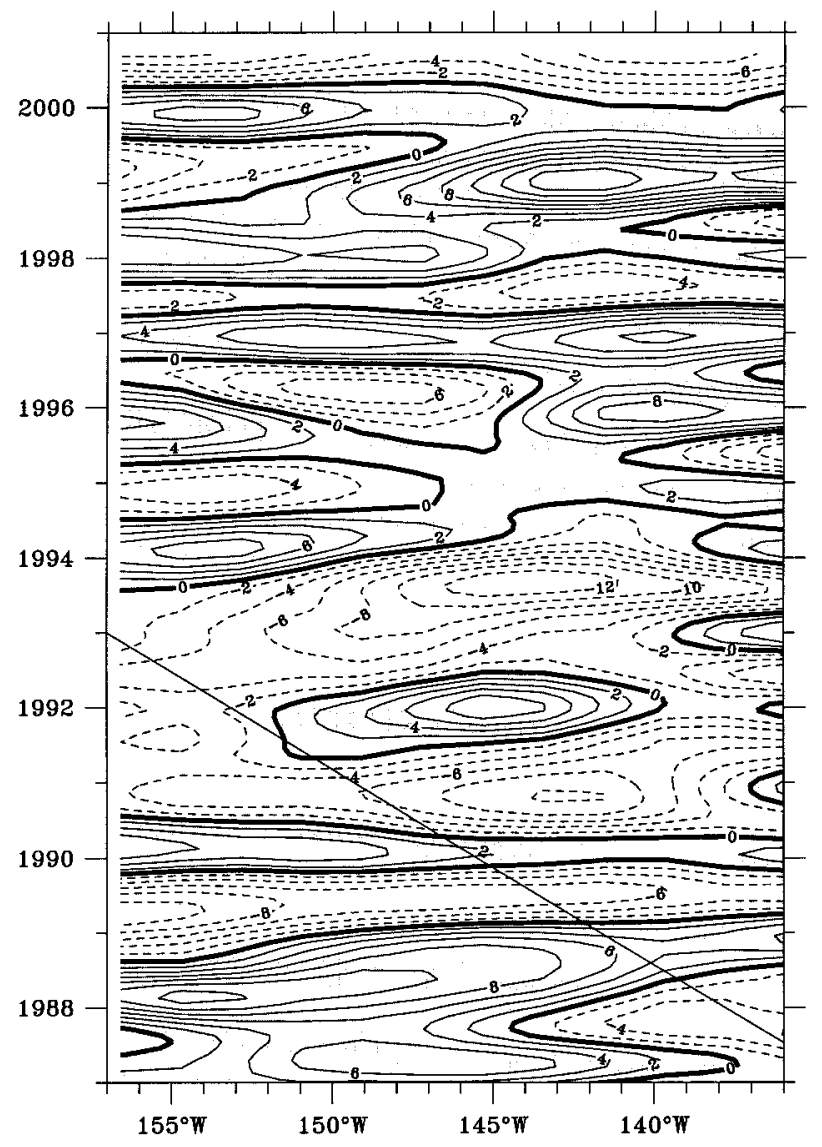

FIG. 12. Wind stress curl anomalies along $53.3^{\circ} \mathrm{N}$ as a function of time and longitude. Units in $10^{-8} \mathrm{~N} \mathrm{~m}^{-1}$. For clarity, signals with periods shorter than 6 months have been removed. The straight thin line denotes the characteristic of long baroclinic Rossby waves at this latitude $\left(c_{R}=-0.80 \mathrm{~cm} \mathrm{~s}^{-1}\right)$. The SSH signal at a point on this line is determined by the wind stress curl forcing accumulated along the characteristic to the east of the point.

correspondence between the SSH anomaly signals along the Alaska/Canada coast and those in the Tropics. This alongshore correspondence in SSH signals has been found by many previous investigators based on tide gauge sea level data analyses (e.g., Enfield and Allen 1980; Chelton and Davis 1982; Emery and Hamilton 1985). It is also noticed by Strub and James (2000b, manuscript submitted to Progress in Oceanography) in their analysis of the T/P data with a focus on 1997-98 El Niño anomalies. While recognizing the impact of the equator-originated SSH anomalies upon those along the midlatitude coast through coastal trapped wave dynamics, the aforementioned investigators have also emphasized the importance of the alongshore SSH changes resulting from local surface wind forcing. The relative importance of these two coexisting forcing mechanisms appears to depend on the geographical distance from the equator. For example, in their analysis of the longterm tide gauge sea level data, Enfield and Allen (1980) noted that "San Fransisco (at $37.8^{\circ} \mathrm{N}$ ) may be a dividing point between stations to the south where sea level is influenced by anomalies of equatorial origin and stations to the north where sea level is influenced by local wind stress anomalies." Interestingly, a close look at Fig. 14 shows some evidence that the T/P SSH anomalies north and south of $38^{\circ} \mathrm{N}$ do have subtly different coherent alongshore structures.

In order to quantify the relative importance of locally and remotely forced SSH changes along the Alaska/ Canada coast, we consider here the dynamic balance proposed by Enfield and Allen (1980) and Chelton and Davis (1982):

$$
\frac{\partial h_{1}^{\prime}}{\partial s}=\frac{\tau_{s}^{\prime}}{\rho_{o} g H_{1}},
$$

where $s$ denotes the alongshore distance and $\tau_{s}^{\prime}$, the alongshore component of the wind stress anomaly vector. Equation (19) can be derived from Eq. (5) by assuming the timescales of interest are long compared with those of the coastal trapped waves. Physically, it represents the balance between the $\tau_{s}^{\prime}$-induced onshore Ekman transport (if $\tau_{s}^{\prime}>0$ ) and the offshore geostrophic transport associated with the alongshore SSH anomaly gradient. For the SSH anomaly averaged along a coast segment from $s_{e}$ to $s_{w}$, integrating Eq. (19) leads to

$\frac{1}{L} \int_{s_{e}}^{s_{w}} h_{1}^{\prime} d s=h_{1}^{\prime}\left(s_{e}\right)+\frac{1}{L} \int_{s_{e}}^{s_{w}} \int_{s_{e}}^{s} \frac{\tau_{s}^{\prime}\left(s^{\prime}\right)}{\rho_{o} g H_{1}} d s^{\prime} d s$,

where $L$ is the length of the coast segment and $h_{1}^{\prime}\left(s_{e}\right)$ is the SSH anomaly at the upstream boundary, $s=s_{e}$. In contrast to this remote upstream signal, the second term on the rhs of Eq. (20) denotes the SSH anomalies forced by the local alongshore wind fluctuations.

In Fig. 15, we compare the observed SSH anomalies averaged along the Alaska/Canada coast from $130^{\circ}$ to $165^{\circ} \mathrm{W}$ with (a) the observed SSH anomalies at the upstream location $s_{e}: 130^{\circ} \mathrm{W}$ and $50^{\circ} \mathrm{N}$, (b) the local alongshore wind-forced SSH anomalies [i.e., the second term on the rhs of Eq. (20)], and (c) the sum of the upstream and locally forced SSH anomalies. The predictive skills of $h_{C}^{\prime}$ by (a), (b), and (c) are $S=$ $-0.12,-1.94$, and 0.35 , respectively. Clearly, it is the combination of the local and upstream forcing that determines the T/P measured SSH anomalies along the Alaska/Canada coast. The importance of this combined forcing, which was also emphasized in the study by Enfield and Allen (1980), is well illustrated by the high SSH anomaly event that appeared from November 1997 to March 1998. After mid-1997, Fig. 15a shows that the SSH anomalies upstream of the Alaska/Canada coast had two maxima with the peaks around July 1997 and February 1998, respectively. This double-maximum signal is "transformed" into a single-maximum signal at the Alaska/Canada coast owing to the locally forced SSH anomalies that have a dominant wintermaximum and summer-minimum annual cycle (Fig. 15b). As shown in Fig. 15c, the single-maximum signal 
(a) dashed line: $\mathbf{h}_{0}$ without steric height removal

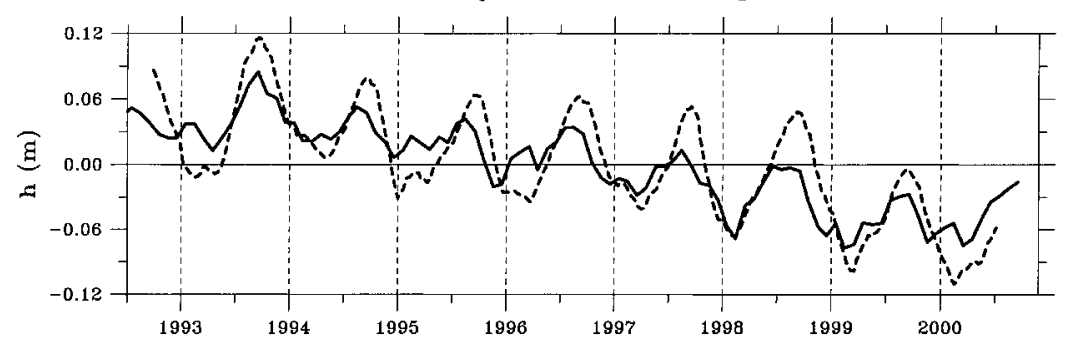

(b) $h_{E k}$ anomalies in offshore Alaska Gyre

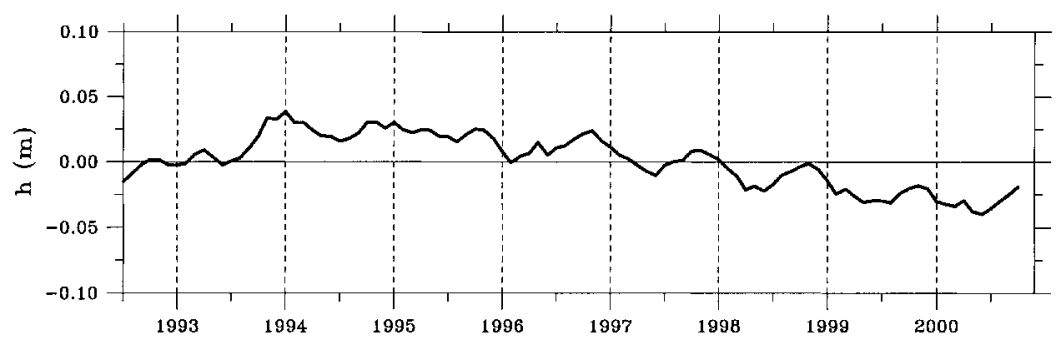

FIG. 13. (a) Solid line: $h_{\mathrm{bt}}^{\prime}+h_{\mathrm{bc}}^{\prime}$ in the offshore Alaska Gyre (same as the solid line in Fig. 11c). Dashed line: T/P SSH anomalies without removal of the steric height signal. (b) SSH anomalies due to anomalous Ekman pumping [Eq. (17)] in the offshore Alaska Gyre.

thus combined matches favorably with the observed $h_{C}^{\prime}$ signal.

Following the 1997-98 El Niño event, the SSH along the Alaska/Canada coast drops and remains at a low level. Figure $15 \mathrm{~b}$ shows that this is in part due to the smaller SSH changes forced by the local alongshore winds during the winters of the succeeding La Niña years. That the Aleutian low over the Alaska gyre tends to weaken following an El Niño event is consistent with the finding by Kelly et al. (1993), who showed that the Aleutian low was weaker in the winters of 1987/88 and $1988 / 89$ as compared to the preceding winter when the 1986-87 El Niño was in the mature phase.

\section{The western subarctic gyre}

The EOF analysis of the T/P SSH anomalies (Fig. 4) shows that the large-scale SSH signals in the WSG region are coherent in three subregions: a northern subregion centered around $47^{\circ} \mathrm{N}$ and $178^{\circ} \mathrm{E}$ wherein the SSH anomalies $\left(h_{N}^{\prime}\right)$ had an increasing trend over the T/ $\mathrm{P}$ period, and southern and western subregions wherein the SSH anomalies $\left(h_{S}^{\prime}\right.$ and $\left.h_{W}^{\prime}\right)$ decreased generally over the T/P period. As shown in Fig. 16a, the time series of $h_{N}^{\prime}$ is characterized by a steplike transition from a relatively low SSH state (1993-95) to a relatively high SSH state (1997-99). In comparison to the $h_{N}^{\prime}$ signals, the interannual trends in $h_{S}^{\prime}$ and $h_{W}^{\prime}$ are opposite and are generally less prominent (Figs. 16b and 16c). Much of the interannual variability we found in the "relative intensity" of the WSG (Fig. 3a) is associated with this steplike change in $h_{N}^{\prime}$. Specifically, the strengthening of the "relative intensity" in 1993-95 is due to the intensification of the eastward flowing Subarctic Current when $h_{N}^{\prime}$ was in the low state and $h_{s}^{\prime}$, the high state. When $h_{N}^{\prime}$ becomes high after 1997, the reduced Subarctic Current contributes to the weakening of the "relative intensity" of the WSG.

Because the large-scale SSH anomaly pattern in the WSG is not aligned with the Levitus mean SSH pattern, caution is needed in interpreting the time series of Fig. 3a. By adding the SSH anomalies of 1993-95 and 1997-99 respectively to the Levitus mean SSH field (Figs. 17a and 17b) we find that the WSG underwent a structural change between these two periods. The WSG was more zonally elongated and accompanied by an intenser Subarctic Current in 1993-95. In contrast, the WSG was more zonally contracted in 1997-99. Although the Subarctic Current was weaker during this latter period, Fig. 17b shows that the western limb of the WSG (the East Kamchatka Current and the Oyashio) was stronger than in 1993-95. The WSG's structural change, of course, results from the large-scale SSH changes in the three subregions of the WSG. Understanding this structural change thus requires clarifying these SSH signals.

In order to understand the $h_{N}^{\prime}$ signals, we plot in Figs. $18 \mathrm{a}$ and $18 \mathrm{~b}$ the barotropic and baroclinic SSH anomalies calculated from Eqs. (16) and (15). Similar to the results of the preceding sections, the $h_{\mathrm{bt}}^{\prime}$ signals are dominated by the annual timescale fluctuations, whereas the $h_{\mathrm{bc}}^{\prime}$ signals capture the SSH changes on interannual timescales. Although the comparison between the observed $h_{N}^{\prime}$ time series and that of $h_{\mathrm{bt}}^{\prime}+h_{\mathrm{bc}}^{\prime}$ appears reasonable 


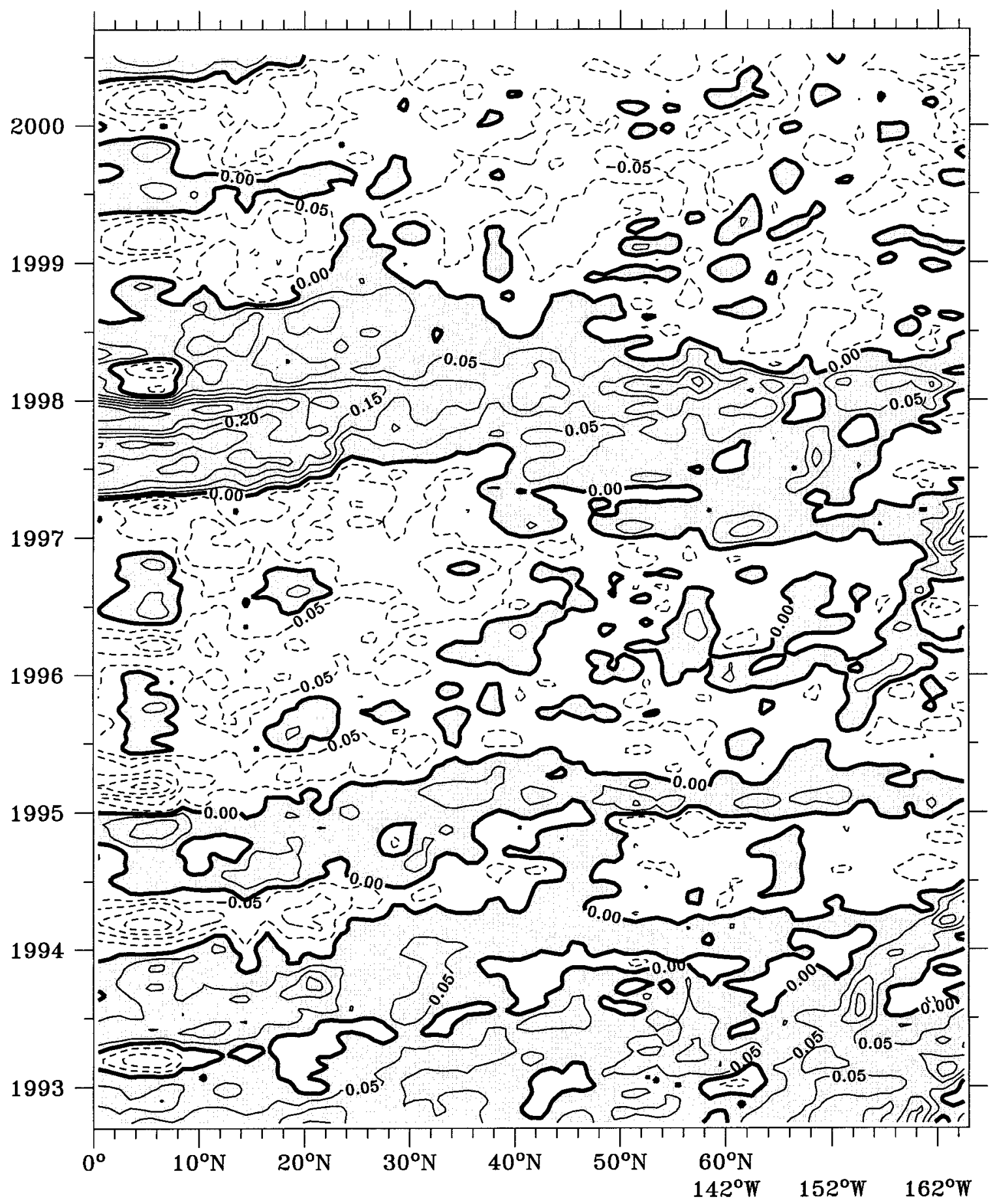

FIG. 14. T/P SSH anomalies averaged within the $1^{\circ}$ band along the Pacific Ocean eastern boundary from the equator to $60^{\circ} \mathrm{N}$ and along the Alaska coast from $142^{\circ}$ to $165^{\circ} \mathrm{W}$ as a function of time. Contour units in $0.05 \mathrm{~m}$.

(Fig. 18c), the predictive skill of $h_{N}^{\prime}$ by $h_{\mathrm{bt}}^{\prime}+h_{\mathrm{bc}}^{\prime}$ in this case is rather low: $S=-0.56$. As is clear in Fig. $18 \mathrm{~b}$, the reason for this low skill is that the baroclinic SSH signal based on Eq. (15) overestimates the interannual change in $h_{N}^{\prime}: h_{\mathrm{bc}}^{\prime}$ was estimated too low in 1993/94 and too high following 1997.
Physically, $h_{\mathrm{bc}}^{\prime}$ is the result of the wind stress curl forcing accumulated over the journey a baroclinic Rossby wave takes from the eastern boundary along the North America coast to the subregion of interest. Because of the slow propagation of the baroclinic Rossby waves at the WSG latitude, the time span of the journey 


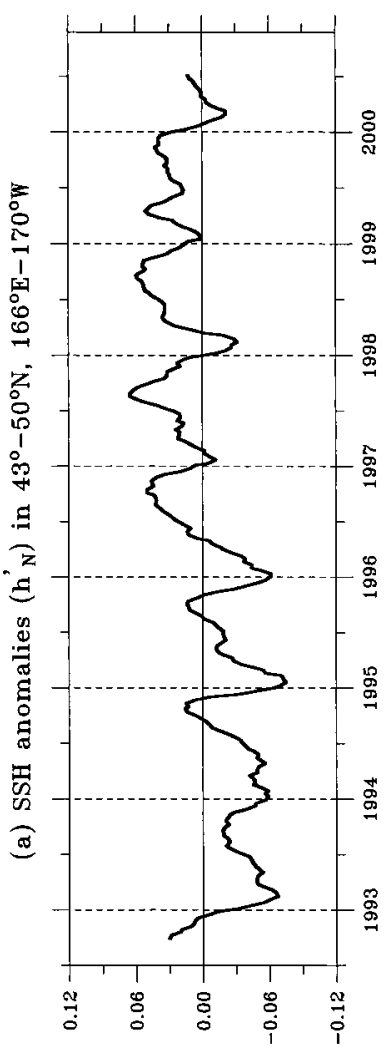

(w) प

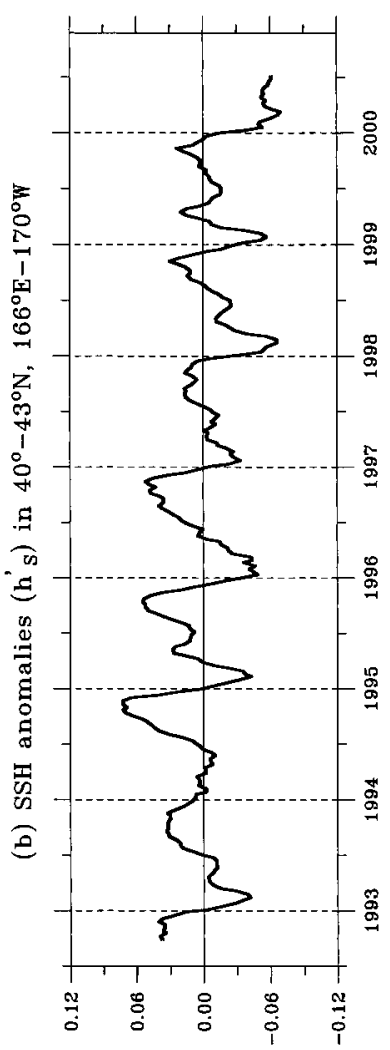

(ux) प

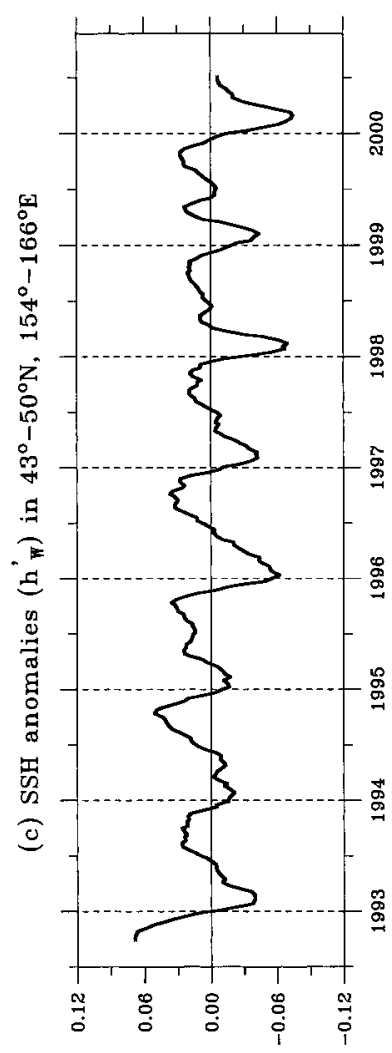

(uI) प

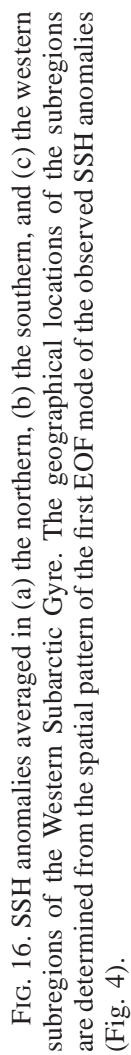

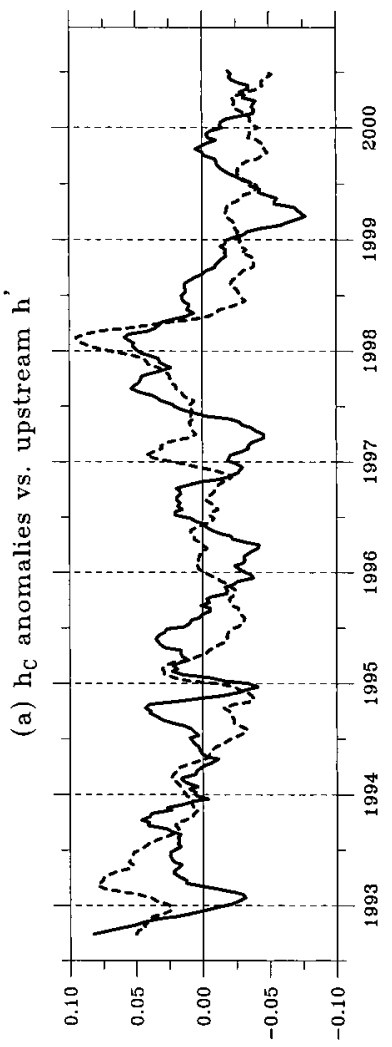

(uI) 4

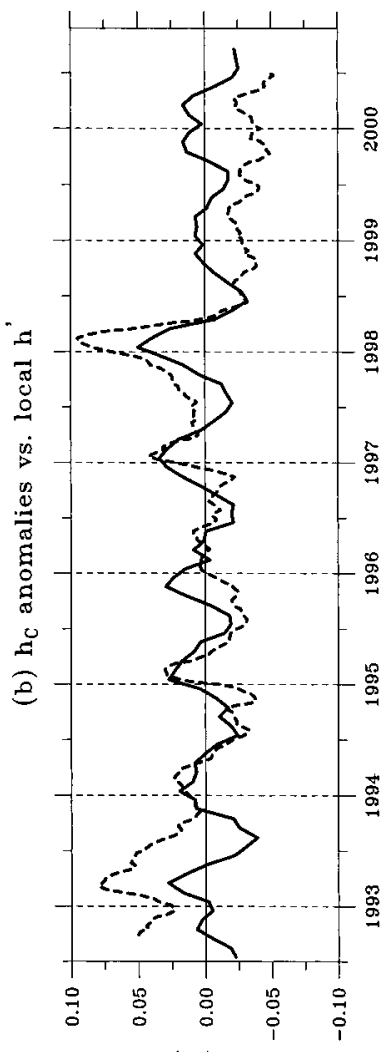

(u) 4

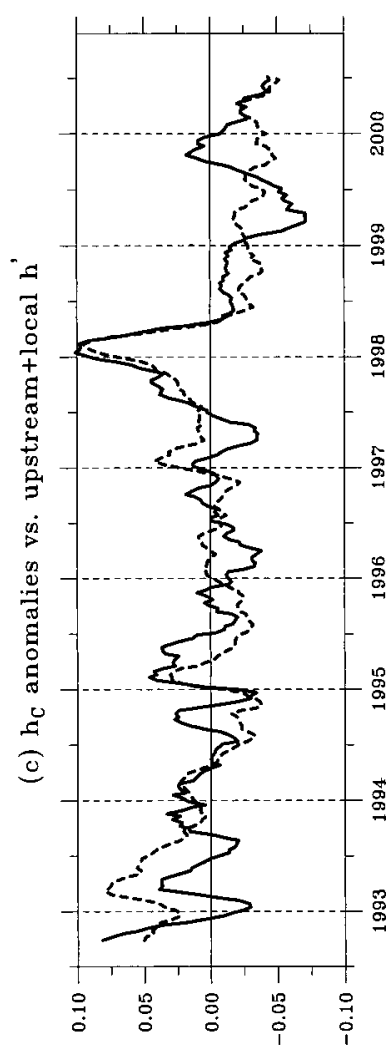

(w) 4
密 올

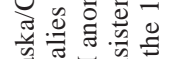

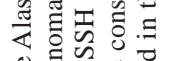
政造

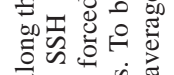

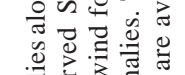

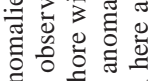

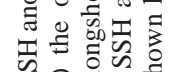

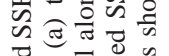

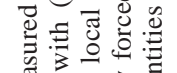
芯令志

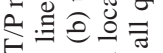

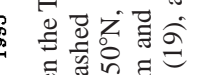

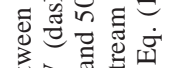

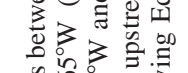

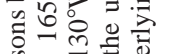

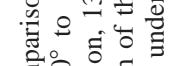

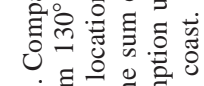

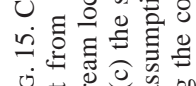

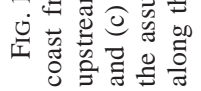


(a) SSH averaged in 1993-1995 (m)

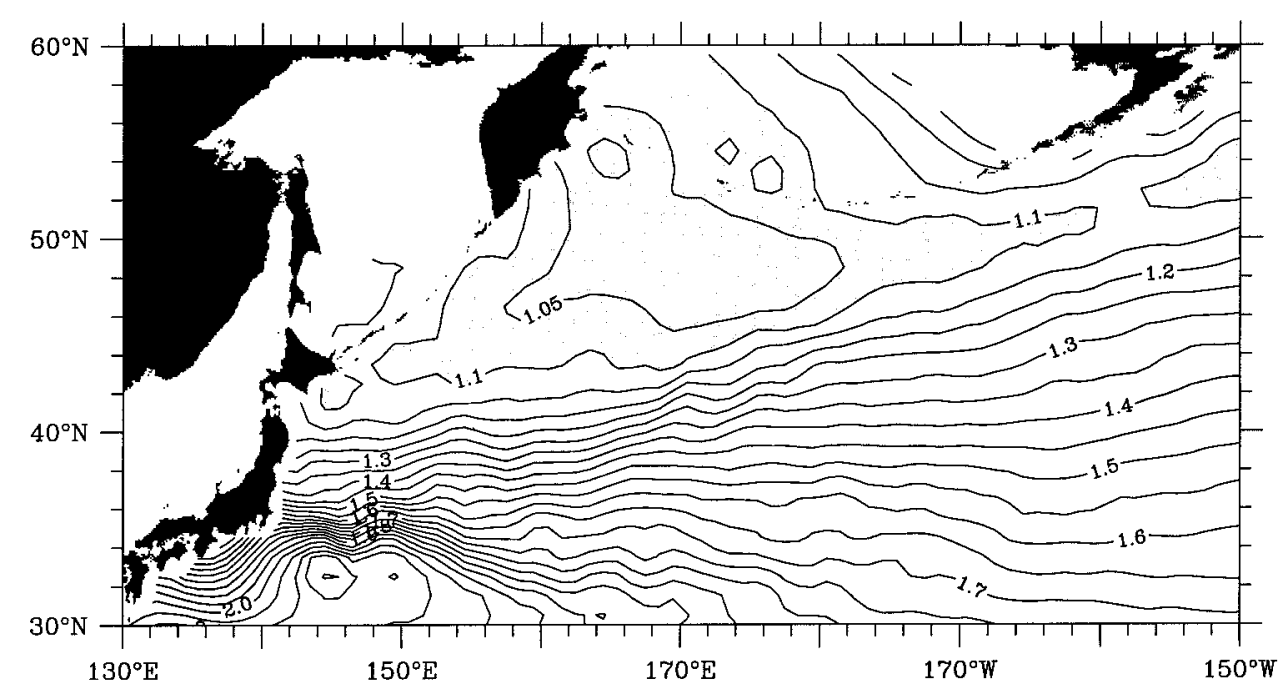

(b) SSH averaged in 1997-1999 (m)

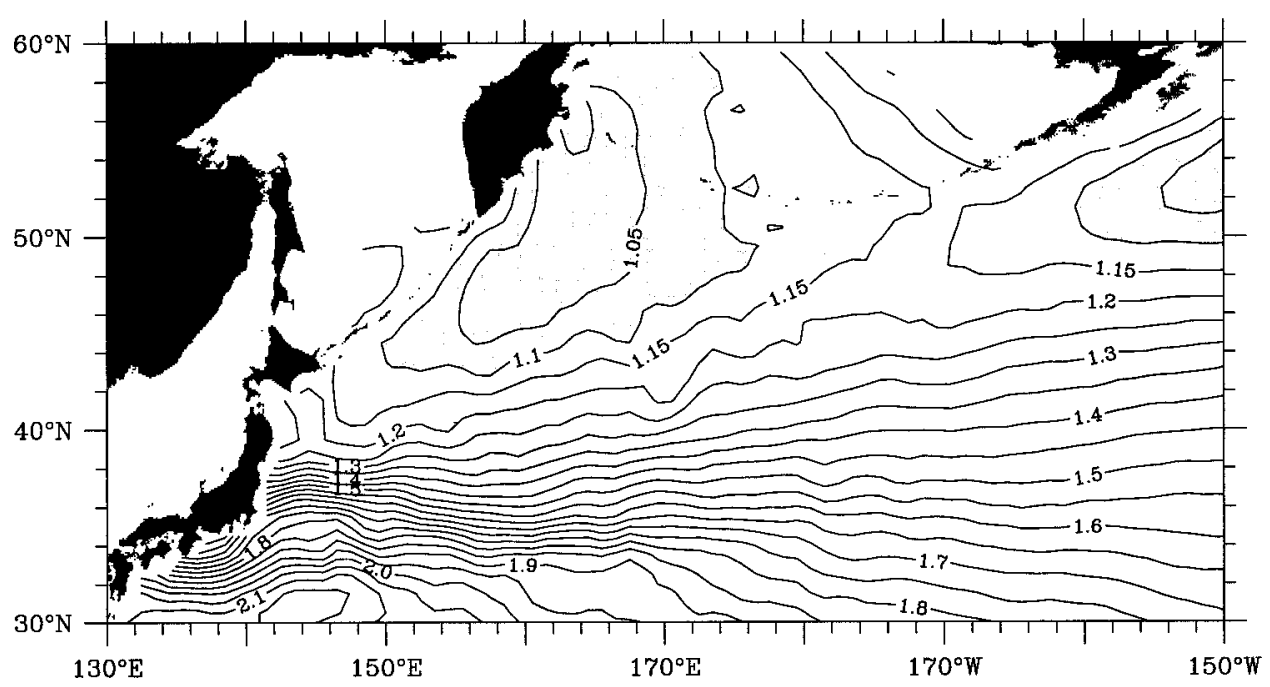

FIG. 17. Sea surface height (mean + anomalies) field averaged in (a) 1993-95 and (b) 1997-99. Here, the mean SSH field is the Levitus climatology (Fig. 1a). Shaded areas have the SSH values $<1.1 \mathrm{~m}$.

is on the order of 15 years. Over such a long journey, it is highly likely that the SSH signals generated in the past will be partially dissipated. In order to quantify how eddy dissipation affects the baroclinic SSH changes, we add a Newtonian dissipation term to Eq. (14):

$$
\frac{\partial h_{\mathrm{bc}}}{\partial t}-\frac{\beta g^{\prime} H_{e}}{f_{o}^{2}} \frac{\partial h_{\mathrm{bc}}}{\partial x}=-\frac{g^{\prime} H_{e}^{2} \boldsymbol{\nabla} \times \boldsymbol{\tau}}{\rho_{o} g f_{o} H_{1}^{2}}-\epsilon h_{\mathrm{bc}},
$$

where $\epsilon$ denotes the Newtonian dissipation rate. Integrating along the baroclinic Rossby wave characteristic, the solution to Eq. (21) is

$$
h_{\mathrm{bc}}(x, t)=h_{\mathrm{bc}}\left(x_{e}, t-\frac{x-x_{e}}{c_{R}}\right) \exp \left[-\frac{\epsilon}{c_{R}}\left(x-x_{e}\right)\right]-\frac{f_{o} H_{e}}{\rho_{o} g \beta H_{1}^{2}} \int_{x_{e}}^{x} \nabla \times \tau\left(x^{\prime}, t-\frac{x-x^{\prime}}{c_{R}}\right) \exp \left[-\frac{\epsilon}{c_{R}}\left(x-x^{\prime}\right)\right] d x^{\prime} .
$$


(a) $\mathrm{h}_{\mathrm{bt}}$ anomalies in $43^{\circ}-50^{\circ} \mathrm{N}, 166^{\circ} \mathrm{E}-170^{\circ} \mathrm{W}$

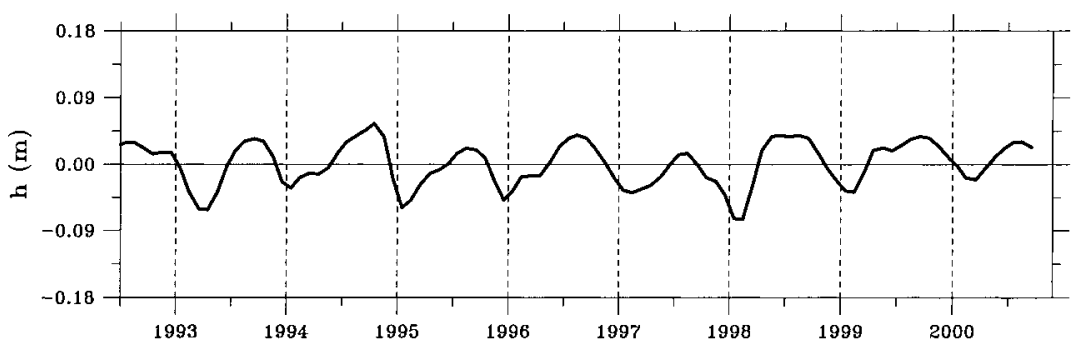

(b) $\mathrm{h}_{\text {be }}$ anomalies in $43^{\circ}-50^{\circ} \mathrm{N}, 166^{\circ} \mathrm{E}-170^{\circ} \mathrm{W}$

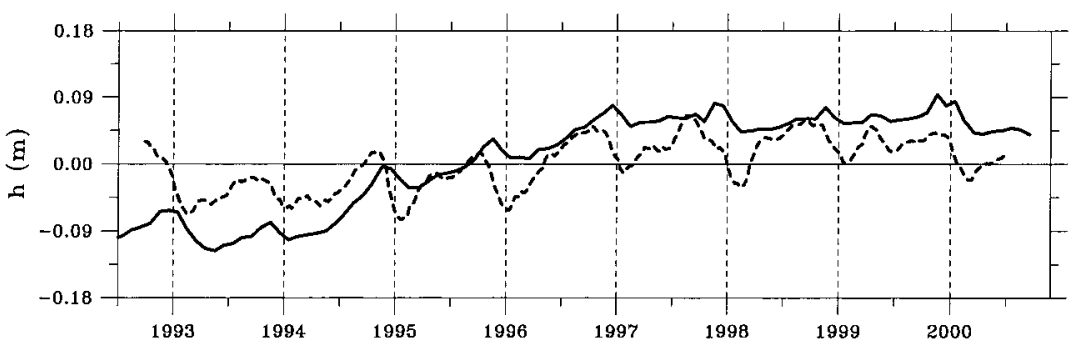

(c) $h_{b c}^{\prime}+h_{b t}^{\prime}$ vs. $h_{N}$ in $43^{\circ}-50^{\circ} \mathrm{N}, 166^{\circ} \mathrm{E}-170^{\circ} \mathrm{W}$

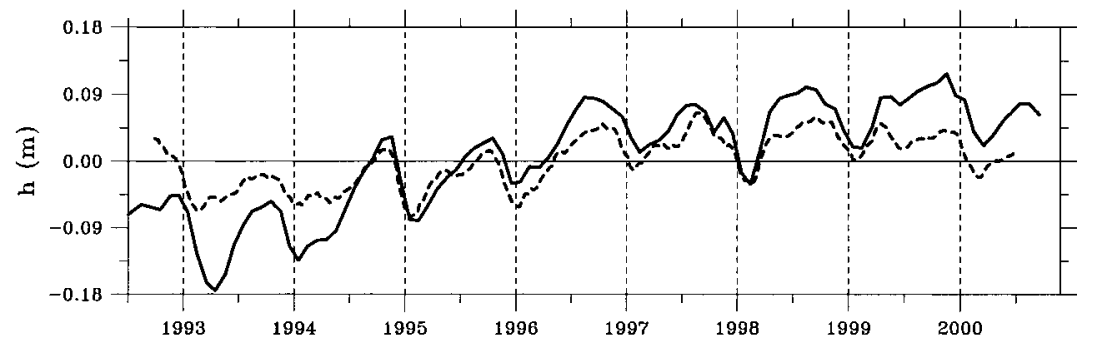

FIG. 18. (a) Barotropic SSH anomalies $h_{\mathrm{bt}}^{\prime}$ in the northern subregion of the WSG calculated from Eq. (16). (b) Solid line: baroclinic SSH anomalies $h_{\mathrm{bc}}^{\prime}$ calculated from Eq. (15). Dashed line: SSH anomalies measured by the T/P altimeters; same as in Fig. 16a. (c) Solid line: $h_{\mathrm{bt}}^{\prime}+h_{\mathrm{bc}}^{\prime}$. Dashed line: SSH anomalies measured by the T/P altimeters.

Since the dissipation rate is a poorly known quantity, we calculate the $h_{\mathrm{bc}}^{\prime}$ signals using a wide range of the $\epsilon$ values. Figure 19a shows the predictive skill of $h_{N}^{\prime}$ by $h_{\mathrm{bt}}^{\prime}+h_{\mathrm{bc}}^{\prime}$ as a function of $\epsilon$. Inclusion of the dissipative effect tends to reduce the magnitude of the $h_{\mathrm{bc}}^{\prime}$ signals and significantly improve the predictive skill. From Fig. 19a, a maximum skill, $S=0.49$, is found when $\epsilon^{-1}=$ $6 \mathrm{yr}$ (compare with $S=-0.56$ for $\epsilon=0$ ). The comparison between $h_{N}^{\prime}$ and the $h_{\mathrm{bt}}^{\prime}+h_{\mathrm{bc}}^{\prime}$ time series calculated using this optimal $\epsilon$ value is shown in Fig. 19b. It is worth noting that the optimal dissipation rate thus estimated is small. This suggests that while eddy dissipation plays an important role for the baroclinic SSH signals in the WSG, it is less important in the NPC and the Alaska gyre regions; baroclinic Rossby waves can traverse these regions from the eastern boundary within the 6-yr $e$-folding timescale of eddy dissipation. By analyzing results from a coupled ocean-atmosphere GCM, Schneider et al. (2002) found that explaining the thermocline changes in the Kuroshio-Oyashio extension region as a result of basin-scale surface wind forcing re- quires the consideration of eddy dissipation. Using a forced baroclinic Rossby wave model, Schneider et al. showed the dissipation rate to be $1 /(4 \mathrm{yr})$, a rate quite similar to the optimal $\epsilon$ value found in this study.

Along the Kuril Islands flow the East Kamchatka Current (EKC) and its southern continuation, the Oyashio. Many previous studies have considered the EKC/Oyashio variability to be constrained by the time-dependent Sverdrup balance. The validity of the Sverdrup balance has been suggested from indicative subsurface water temperature data (Sekine 1988; Hanawa 1995), seasonal hydrographic observations (Kono and Kawasaki 1997), and the SSH-derived Oyashio transport based on the first 2yr T/P data (Isoguchi et al. 1997). While it is well established that the EKC/Oyashio transport is in phase with the Sverdrup transport on the annual timescale, the question of whether the time-dependent Sverdrup balance also explains the interannual changes in the EKC/Oyashio is unanswered. As we have found throughout this study, baroclinic processes are important for the large-scale interannual SSH signals. As such, we cannot take for grant- 
(a) predictive skill vs. dissipation rate

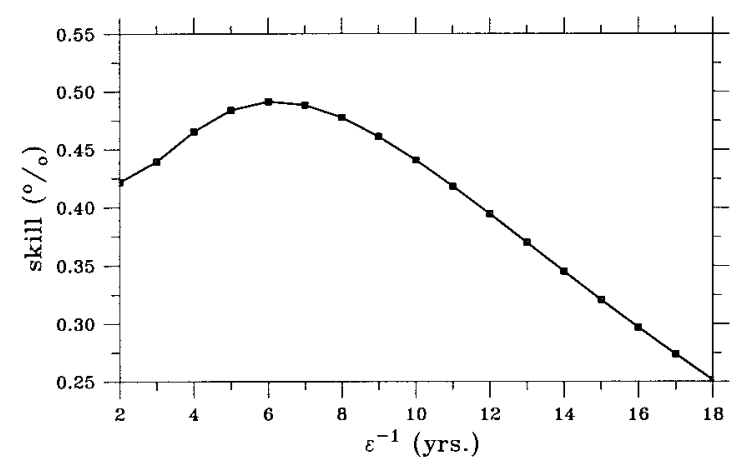

(b) $h_{b c}^{\prime}+h_{b t}^{\prime}$ vs. $h_{N}^{\prime}\left(\varepsilon^{-1}=6 y r s.\right)$

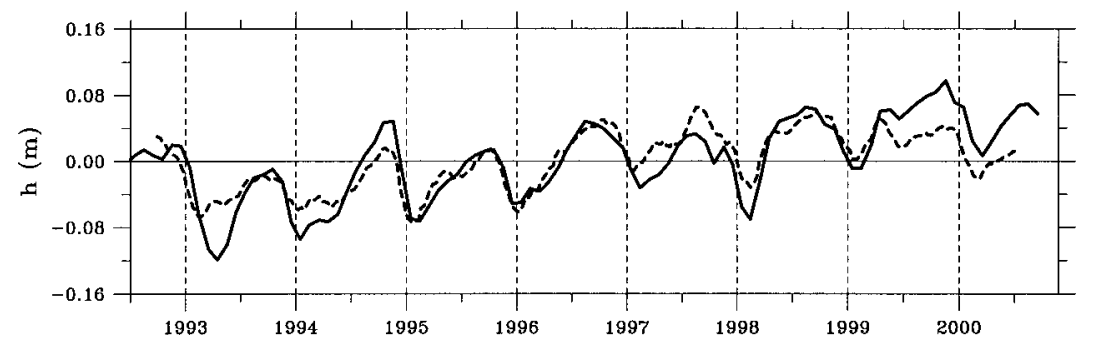

FIG. 19. (a) Predictive skill of the observed SSH anomalies in the northern subregion of the WSG $\left(h_{N}^{\prime}\right)$ by $h_{\mathrm{bt}}^{\prime}+h_{\mathrm{bc}}^{\prime}$ as a function of the dissipation rate $\epsilon$. Here, $h_{\mathrm{bc}}^{\prime}$ is calculated from Eq. (22). (b) Comparison between $h_{N}^{\prime}$ (dashed line) and $h_{\mathrm{bt}}^{\prime}+h_{\mathrm{bc}}^{\prime}$ (solid line) when $\epsilon^{-1}=6 \mathrm{yr}$.

ed that the time-dependent Sverdrup balance should be valid beyond the annual timescale.

To address this question, we first quantify the variability of the EKC/Oyashio. Figures 20a and 20b show the SSH anomalies averaged in the two $2^{\circ}$-wide bands bracketing the EKC/Oyashio from $43^{\circ}$ to $51^{\circ} \mathrm{N}$. From the difference between these two time series, we plot in Fig. 20c the surface velocity anomalies of the EKC/ Oyashio. Because of the abundance of mesoscale eddies offshore of the Kuril Islands (Talley 1991; Rogachev 2000; Yasuda et al. 2000), we are using the alongboundary averaged velocity anomalies to represent the EKC/Oyashio variability. Notice that the offshore band $\left(h_{O}^{\prime}\right)$ has, in general, larger and better defined annualto-interannual SSH changes than its coastal counterpart $\left(h_{C}^{\prime}\right)$ and that the EKC/Oyashio velocity anomaly is largely determined by $h_{O}^{\prime}$.

In Fig. 21a, we plot the Sverdrup transport anomalies averaged from $43^{\circ}$ to $51^{\circ} \mathrm{N}$ by integrating the NCEP wind stress curl data from the eastern boundary to offshore of the Kuril Islands. To compare this time series with the SSH-derived EKC/Oyashio velocity time series, we scale the Sverdrup transport value by -0.0026 $\mathrm{m} \mathrm{s}^{-1} \mathrm{~Sv}^{-1}$ and superimpose the two time series in Fig. $21 \mathrm{~b}$. Here, the scaling factor is determined by maximizing the predictive skill of the SSH-derived EKC/ Oyashio velocity by the Sverdrup velocity. As shown in Fig. 21b, the annual cycle of the EKC/Oyashio velocity agrees very well with that of the scaled Sverdrup velocity. The Sverdrup signal appears also to capture some of the year-to-year changes in the wintertime EKC/ Oyashio velocity peaks. For example, both time series show that the velocity peaks in 1993, 1995, 1996, and 1998 are larger than those in 1994, 1997, and 1999. Notwithstanding these agreements, Fig. $21 \mathrm{~b}$ reveals that a lower-frequency difference exists between the two time series. As indicated by the solid line in Fig. 21c, the scaled Sverdrup velocity is consistently larger than the observed EKC/Oyashio velocity in 1992-95, whereas it is consistently smaller in 1996-98.

Could this low-frequency difference in the velocity be explained by the baroclinic ocean responses that are ignored in the time-dependent Sverdrup balance? To clarify this, we calculate the baroclinic SSH anomalies, $h_{\mathrm{bc}}^{\prime}$, in the offshore band of the Kuril Islands from Eq. (22). (From the result shown in Fig. 19, $\epsilon^{-1}=6 \mathrm{yr}$ is again used.) The dashed line in Fig. 21c shows the surface EKC/Oyashio velocity changes induced by the offshore baroclinic SSH anomalies (i.e., $-g h_{\mathrm{bc}}^{\prime} / f W$ ). The time series has a low-frequency signal very similar to that of the solid line (the linear correlation coefficient between the two time series in Fig. 21c is 0.69). Specifically, in 1993-95 the baroclinic Rossby wave responses increase the SSH offshore of the Kuril Islands and work to weaken the surface EKC/Oyashio velocity, whereas in 1996-98 the SSH anomalies offshore of the Kuril Islands is lowered by the baroclinic Rossby wave processes, giving rise to a stronger EKC/Oyashio velocity. The result of 


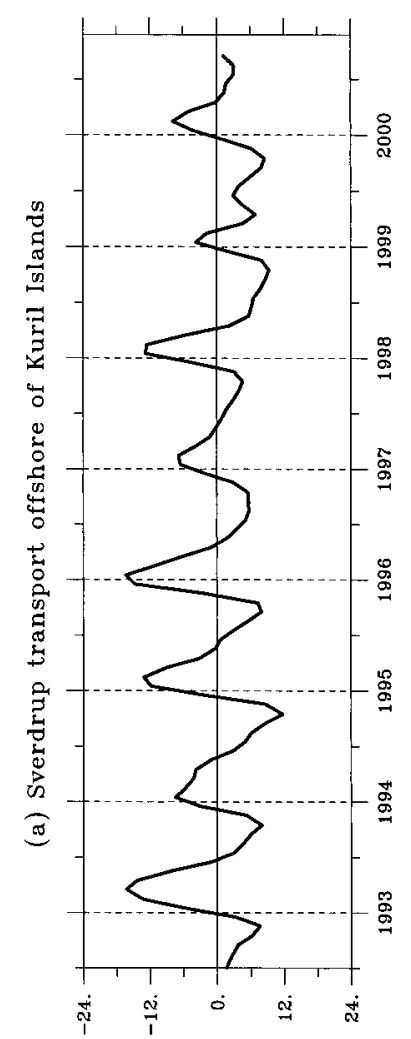

(AS) prodsuex?
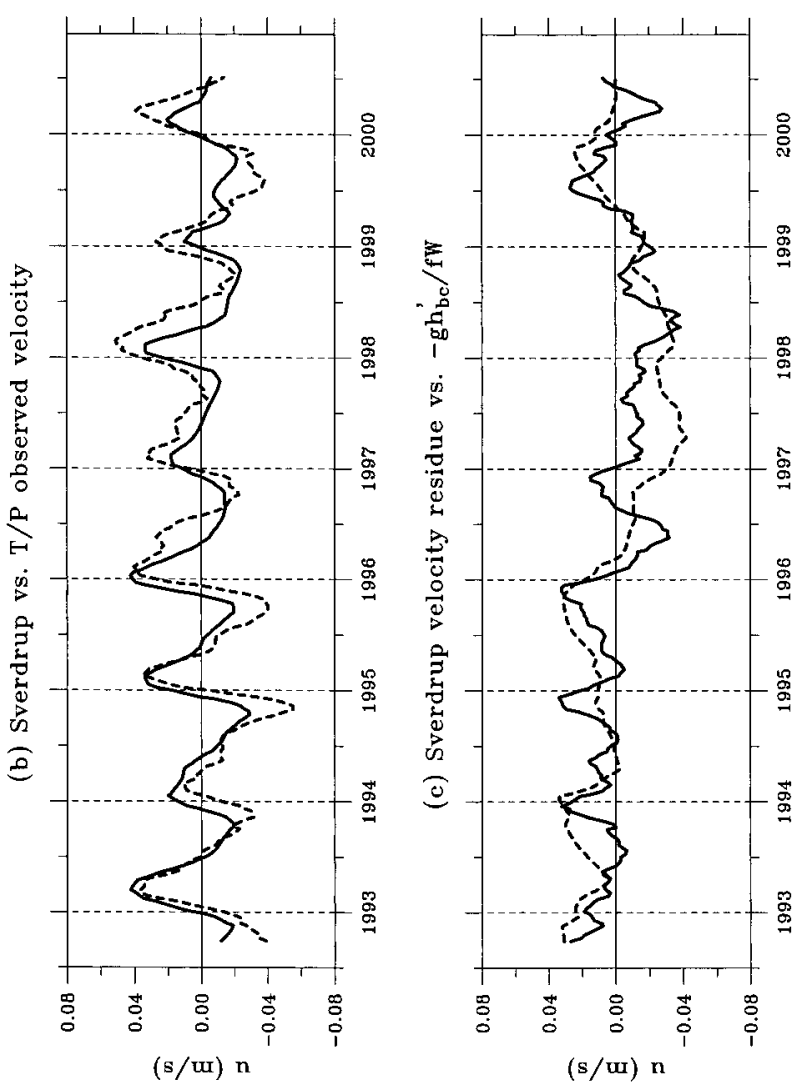

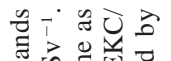

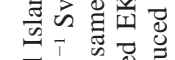

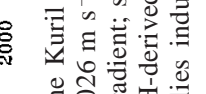

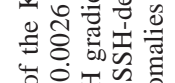

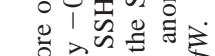

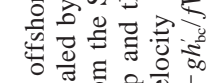
罚 D

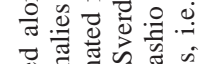
-

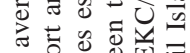

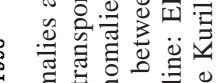

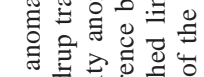

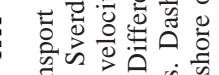

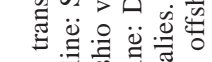

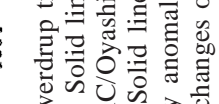
旅光的焉

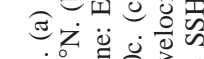
규월

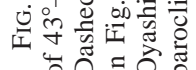
(s/w) n

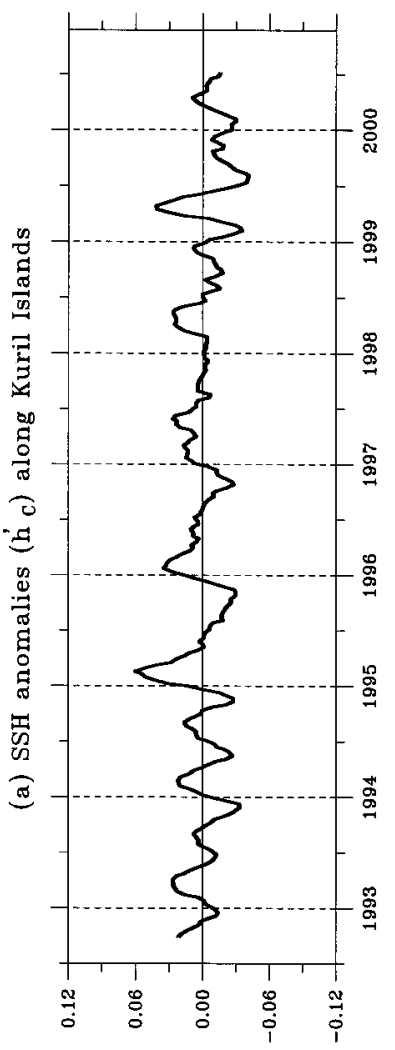

(w) प

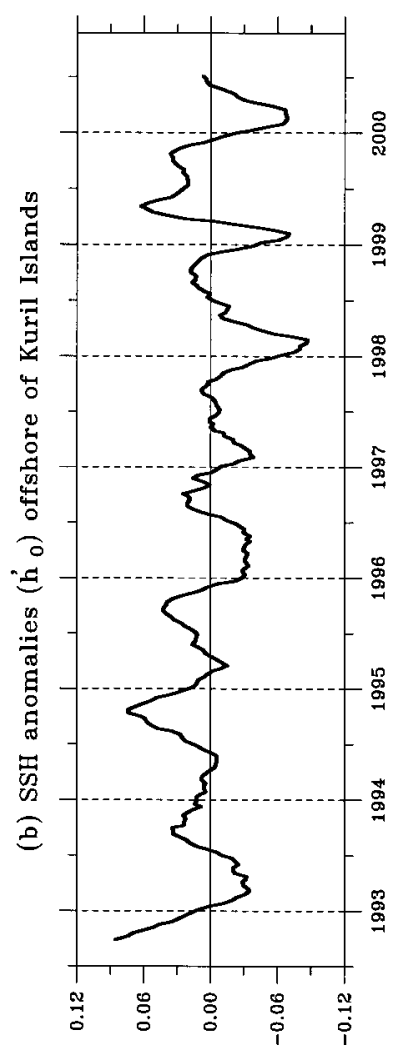

(w) 4

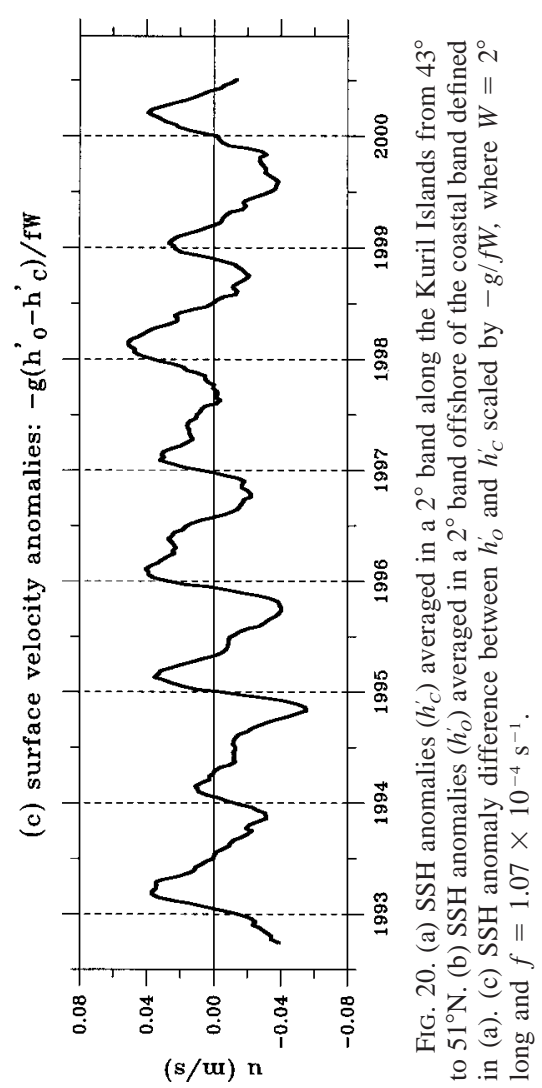


Fig. 21 suggests that while the barotropic Sverdrup responses are responsible for the EKC/Oyashio variability on the annual and year-to-year timescales, contributions from the baroclinic Rossby wave responses are important on the multiyear timescales.

\section{Summary}

Altimetric observations from the TOPEX/Poseidon satellite over the past eight years provide us an unprecedented sea surface height dataset to investigate the ocean circulation changes on various timescales. Using this dataset, we examined the large-scale circulation changes in the midlatitude North Pacific Ocean. Particular attention was paid to the North Pacific Current, the Alaska gyre, and the western subarctic gyre. In addition to the description of the large-scale changes in these current systems, the goal of this study was to construct a dynamic framework that can aid our understanding of the observed circulation changes on the seasonal-to-interannual timescales. To achieve this goal, we adopted a two-layer ocean model that takes into account the firstmode baroclinic Rossby wave dynamics and the timedependent barotropic Sverdrup dynamics. Though simple in dynamics, we found that this model is adequate to reproduce many of the observed large-scale SSH signals. The baroclinic Rossby wave dynamics explain the interannual SSH changes consistently in all of the three current systems of our interest. Similarly, the barotropic Sverdrup dynamics are responsible for the observed SSH signals on the annual and shorter timescales.

The large-scale variability in the North Pacific Current is dominated by its steady strengthening over the period from late 1992 to 1998 . Much of this interannual signal is due to the large-scale SSH dropping on the northern side of the NPC. With the slow propagation of the baroclinic Rossby waves at the NPC latitude and with its presence near the eastern boundary, the interannual signal in the NPC at a particular time depends on the regional wind stress curl forcing accumulated over the years prior to that time. Because the large-scale SSH signals throughout the NPC region have similar annual variations, the intensity of the NPC itself exhibits no clear modulation on the annual timescale.

In the Alaska gyre interior, the SSH anomalies show a similar interannually decreasing trend as in the northern NPC region. In other words, the Alaska gyre interior shoaled steadily over the period from 1993 to 1999. The intensity of the Alaska gyre, however, depends not only on the interior SSH anomalies, but also on those along the Alaska/Canada coast. We found that the SSH anomalies along the Alaska/Canada coast are determined by a combination of remotely and locally forced signals. The alongshore SSH was anomalously high during the 1997-98 El Niño event (Aug 1997-Mar 1998) and dropped to a persistently low level immediately following the El Niño event. In addition to the interannual signal, the intensity of the Alaska gyre also has a well- defined annual cycle: a maximum in January-March and a minimum in July-September. This annual cycle is a consequence of the barotropic Sverdrup response of the Alaska gyre to the seasonally varying surface wind stress curl forcing.

The intensity of the western subarctic gyre also undergoes a noticeable annual modulation with a winter maximum and a summer minimum. Like the Alaska gyre, the amplitude and phase of the modulation are determined by the time-dependent barotropic Sverdrup balance. Interannually, the WSG transformed from a zonally elongated gyre in 1993-95 to a zonally more contracted gyre in 1997-99. The elongated WGS had the more intense eastward flowing Subarctic Current, whereas the contracted WSG, with the gyre center shifted westward, had the more intense East Kamchatka Current and Oyashio. This structural change of the WSG is due to the steady SSH rise in the northern subregion of the WSG and the steady SSH drop in its southern and western subregions. Although the baroclinic Rossby wave dynamics are again important for these interannual SSH changes, we found that to adequately simulate the observed SSH trends requires taking into account the eddy dissipation effect. By maximizing predictive skill, we estimated the timescale for the Newtonian dissipation rate to be about six years. Dynamically, this implies that the wind stress curl forcing over the eastern Alaska gyre exerts less of an influence upon the interannual changes of the WSG than does the forcing over the western Alaska gyre. For the western boundary currents in the subpolar North Pacific, we found that the EKC/ Oyashio variability is in balance with the interior Sverdrup flow variability on the annual and year-to-year timescales. On the multiyear timescales, the SSH signals governed by the baroclinic Rossby wave dynamics are important in explaining the low-frequency modulation of the EKC/Oyashio changes that is unaccounted for by the barotropic Sverdrup balance.

Acknowledgments. This study benefited from many discussions with Ted Durland, John Hargrove, Humio Mitsudera, and Ted Strub. Detailed comments made by Lynne Talley and an anonymous reviewer helped clarify many parts of an early version of the manuscript. The surface wind stress and heat flux data were provided by the National Center for Environmental Prediction and the TOPEX/Poseidon data, by the Physical Oceanography DAAC at Jet Propulsion Laboratory. I am grateful to Gary Mitchum for his help in processing the original T/P data. Support from NASA through the TOPEX/ Poseidon Extended Mission (Contract 960889) and the Jason1 project (Contract 1207881) is gratefully acknowledged.

\section{REFERENCES}

Bhaskaran, S., G. S. E. Lagerloef, G. H. Born, W. J. Emery, and R. R. Leben, 1993: Variability in the Gulf of Alaska from Geosat altimetry data. J. Geophys. Res., 98, 16 311-16 330. 
Callahan, P. S., 1993: TOPEX/POSEIDON GDR user handbook. Jet Propulsion Laboratory Special Publication D-8944, 84 pp.

Chelton, D. B., and R. E. Davis, 1982: Monthly mean sea-level variability along the west coast of North America. J. Phys. Oceanogr., 12, 757-784.

_ - R. A. DeSzoeke, M. G. Schlax, K. E. Naggar, and N. Siwertz, 1998: Geographical variability of the first baroclinic Rossby radius of deformation. J. Phys. Oceanogr., 28, 433-460.

Deser, C., and M. L. Blackmon, 1995: On the relationship between tropical and North Pacific sea surface variations. J. Climate, 8, 1677-1680.

Emery, W. J., and K. Hamilton, 1985: Atmospheric forcing of interannual variability in the northeast Pacific Ocean. J. Geophys. Res., 90, 857-868.

Enfield, D. B., and J. S. Allen, 1980: On the structure and dynamics of monthly mean sea level anomalies along the Pacific coast of North and South America. J. Phys. Oceanogr., 10, 557-578.

Favorite, F., A. J. Dodimead, and K. Nasu, 1976: Oceanography of the subarctic Pacific region, 1962-72. Bull. Int. North Pac. Fish. Comm., 33, 1-187.

Fu, L.-L., and R. A. Davidson, 1995: A note on the barotropic response of sea level to time-dependent wind forcing. J. Geophys. Res., 100, 24 955-24 963.

Fukumori, I., R. Raghunath, and L.-L. Fu, 1998: Nature of global large-scale sea level variability in relation to atmospheric forcing: A model study. J. Geophys. Res., 103, 5493-5512.

Gill, A., and P. P. Niiler, 1973: The theory of the seasonal variability in the ocean. Deep-Sea Res., 20, 141-177.

Gilson, J., D. Roemmich, B. Cornuelle, and L.-L. Fu, 1998: Relationship of TOPEX/Poseidon altimetric height to steric height and circulation in the North Pacific. J. Geophys. Res., 103, 27 947-27 965.

Hanawa, K., 1995: Southward penetration of the Oyashio water system and the wintertime condition of midlatitude westerlies over the North Pacific. Bull. Hokkaido Natl. Fish. Res. Inst., 59, 103119.

Isoguchi, O., H. Kawamura, and T. Kono, 1997: A study on winddriven circulation in the subarctic North Pacific using TOPEX/ POSEIDON altimeter data. J. Geophys. Res., 102, 12 457-12 468.

Kalnay, E., and Coauthors, 1996: The NCEP/NCAR 40-Year Reanalysis Project. Bull. Amer. Meteor. Soc., 77, 437-471.

Kawai, H., 1972: Hydrography of the Kuroshio Extension. Kuroshio-Its Physical Aspects, H. Stommel and K. Yoshida, Eds., University of Tokyo Press, 235-354.

Kelly, K. A., M. J. Caruso, and J. A. Austin, 1993: Wind-forced variations in sea surface height in the northeast Pacific Ocean. J. Phys. Oceanogr., 23, 2392-2411.

Killworth, P. D., D. B. Chelton, and R. A. De Szoeke, 1997: The speed of observed and theoretical long extratropical planetary waves. J. Phys. Oceanogr., 27, 1946-1966.

Koblinsky, C. J., P. P. Niiler, and W. J. Schmitz Jr., 1989: Observations of wind-forced deep ocean currents in the North Pacific. J. Geophys. Res., 94, 10 773-10 790.

Kono, T., and Y. Kawasaki, 1997: Results of CTD and mooring observations southeast of Hokkaido. 1. Annual velocity and transport variations in the Oyashio. Bull. Hokkaido Natl. Fish. Res. Inst., 61, 65-81.

Lagerloef, G., 1995: Interdecadal variations in the Alaska Gyre. J. Phys. Oceanogr., 25, 2242-2258.

Levitus, S., and T. Boyer, 1994: World Ocean Atlas 1994. Vol 4: Temperatures, NOAA Atlas NESDIS 4, U.S. Govt Printing Office, Washington, $117 \mathrm{pp}$.

__ R. Burgett, and T. Boyer, 1994: World Ocean Atlas 1994. Vol 3: Salinity, NOAA Atlas NESDIS 3, U.S. Govt Printing Office, Washington, 99 pp.
Miller, A. J., D. R. Cayan, T. P. Barnett, N. E. Graham, and J. M. Oberhuber, 1994: Interdecadal variability of the Pacific Ocean: Model response to observed heat flux and wind stress anomalies. Climate Dyn., 9, 287-302.

Mizuno, K., and W. B. White, 1983: Annual and interannual variability in the Kuroshio Current system. J. Phys. Oceanogr., 13, 1847-1867

Musgrave, D. L., T. J. Weingartner, and T. C. Royer, 1992: Circulation and hydrography in the northwestern Gulf of Alaska. Deep-Sea Res., 39, 1499-1519.

Nakamura, H., G. Lin, and T. Yamagata, 1997: Decadal climate variability in the North Pacific during the recent decades. Bull. Amer. Meteor. Soc., 78, 2215-2225.

Qiu, B., 1995: Variability and energetics of the Kuroshio Extension and its recirculation gyre from the first two-year TOPEX data. J. Phys. Oceanogr., 25, 1827-1842.

_ 2000: Interannual variability of the Kuroshio Extension and its impact on the wintertime SST field. J. Phys. Oceanogr., 30, 1486-1502.

Reed, R. K., 1984: Flow of the Alaskan Stream and its variations. Deep-Sea Res., 31, 369-386.

Rienecker, M. M., and L. L. Ehret, 1988: Wind stress curl variability over the North Pacific from the Comprehensive Ocean-Atmosphere Data Set. J. Geophys. Res., 93, 5069-5077.

Rogachev, K. A., 2000: Recent variability in the Pacific western subarctic boundary currents and Sea of Okhotsk. Progress in Oceanography, Vol. 47, Pergamon, 209-336.

Royer, T. C., 1979: On the effect of precipitation and runoff on coastal circulation in the Gulf of Alaska. J. Phys. Oceanogr., 9, 555563.

- 1981: Baroclinic transport in the Gulf of Alaska. Part I. Seasonal variations of the Alaska Current. J. Mar. Res., 39, 239250.

Schneider, N., A. J. Miller, and D. W. Pierce, 2002: Anatomy of North Pacific decadal variability. J. Climate, in press.

Sekine, Y., 1988: Anomalous southward intrusion of the Oyashio east of Japan. 1. Influence of the seasonal and interannual variations in the wind stress over the North Pacific. J. Geophys. Res., 93, 2247-2255.

Stammer, D., 1997: Steric and wind-induced changes in TOPEX/ POSEIDON large-scale sea surface topography observations. $J$. Geophys. Res., 102, 20 987-21 009.

Tabata, S., 1991: Annual and interannual variability of baroclinic transports across Line $\mathrm{P}$ in the northeast Pacific Ocean. DeepSea Res., 38, S221-S245.

, B. Thomas, and D. Ramsden, 1986: Annual and interannual variability of steric sea level along Line $\mathrm{P}$ in the northeast Pacific Ocean. J. Phys. Oceanogr., 16, 1378-1398.

Talley, L. D., 1991: An Okhotsk sea water anomaly: Implications for ventilation in the North Pacific. Deep-Sea Res., 38, S171-S190.

Vivier, F., K. A. Kelly, and L. Thompson, 1999: The contributions of wind forcing, waves, and surface heating to sea surface height observations in the Pacific Ocean. J. Geophys. Res., 104, $20767-20788$.

Wang, L., and C. J. Koblinsky, 1996: Annual variability of the subtropical recirculations in the North Atlantic and North Pacific: A TOPEX/POSEIDON study. J. Phys. Oceanogr., 26, 24622479.

White, W. B., 1982: Traveling wave-like mesoscale perturbations in the North Pacific Current. J. Phys. Oceanogr., 12, 231-243.

Willebrand, J., S. G. H. Philander, and R. C. Pacanowski, 1980: The oceanic response to large-scale atmospheric disturbances. $J$. Phys. Oceanogr., 10, 411-429.

Yasuda, I., and Coauthors, 2000: Cold-core anticyclonic eddies south of the Bussol' Strait in the northwestern Subarctic Pacific. J. Phys. Oceanogr., 30, 1137-1157. 